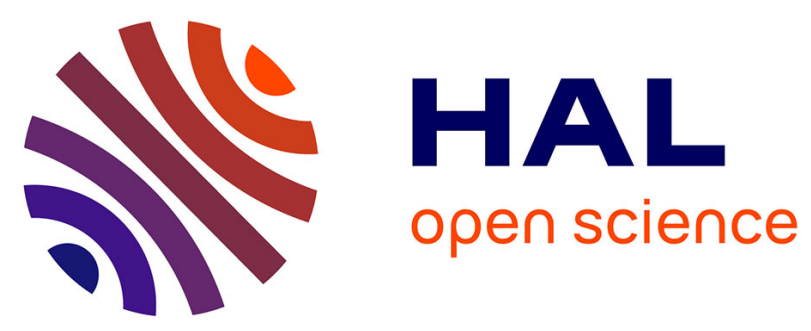

\title{
MATLAB in electrochemistry: A review
}

Ali R Jalalvand, Farid Najafi, Douglas Rutledge, Hector C Goicoechea, Hui-Wen Gu

\section{To cite this version:}

Ali R Jalalvand, Farid Najafi, Douglas Rutledge, Hector C Goicoechea, Hui-Wen Gu. MATLAB in electrochemistry: A review. Talanta, 2019, 194, pp.205-225. 10.1016/j.talanta.2018.10.041 . hal02317791

HAL Id: hal-02317791

https://hal-agroparistech.archives-ouvertes.fr/hal-02317791

Submitted on 18 Oct 2019

HAL is a multi-disciplinary open access archive for the deposit and dissemination of scientific research documents, whether they are published or not. The documents may come from teaching and research institutions in France or abroad, or from public or private research centers.
L'archive ouverte pluridisciplinaire HAL, est destinée au dépôt et à la diffusion de documents scientifiques de niveau recherche, publiés ou non, émanant des établissements d'enseignement et de recherche français ou étrangers, des laboratoires publics ou privés. 
Elsevier Editorial System(tm) for Talanta Manuscript Draft

Manuscript Number:

Title: MATLAB in Electrochemistry: A review

Article Type: Review Paper

Keywords: MATLAB; Electrochemistry; Quantitative and qualitative information; Solving of problem.

Corresponding Author: Dr. Ali R. Jalalvand, Ph.D.

Corresponding Author's Institution: Kermanshah University of Technology

First Author: Ali R. Jalalvand, Ph.D.

Order of Authors: Ali R. Jalalvand, Ph.D.; Farid Najafi; Hector C. Goicoechea; Hui-Wen Gu

Abstract: MATLAB (MATrix LABoratory) is a multi-paradigm numerical computing environment and fourth-generation programming language. MATLAB allows matrix manipulations, plotting of functions and data, implementation of algorithms, creation of user interfaces, and interfacing with programs written in other languages, including $\mathrm{C}, \mathrm{C}++$, Java, Fortran and Python. Electrochemistry is a branch of chemistry that studies the relationship between electricity, as a measurable and quantitative phenomenon, and identifiable chemical change, with either electricity considered an outcome of a particular chemical change or vice versa. MATLAB has obtained a wide range of applications in different fields of science and electrochemists are also using it for solving their problems which help them to obtain more quantitative and qualitative information about systems under their studies. In this review, we are going to cast a look on different applications of MATLAB in electrochemistry and for each section, a number of selected articles published in the literature will be discussed and finally, the results will be summarized and concluded. 


\section{Dear Editor,}

Hereby, I confirm submission of a manuscript entitled "MATLAB in Electrochemistry: A review" to Talanta and I would like you to consider it for publication. This is a review article and is not currently submitted to any other Journal, and will not be submitted elsewhere before a decision is made by this Journal.

\section{Sincerely Yours,}
Ali R. Jalalvand, $\mathrm{PhD}$
Assistant Professor, Research Center of Oils and Fats (RCOF), Food and Drug Administration (FDA), Kermanshah University of Medical Sciences, Kermanshah, Iran
Tel: +988334302345
Fax: +98 8334279745 
According to the experience of our research group we have provided an interesting and through review article which reflects the applications of a well-known software namely MATLAB in electrochemical projects. This review is very useful for expanding applications of MATLAB in electrochemistry. 
$\checkmark$ Required information to understand the review was collected.

$\checkmark$ Chemometrics links MATLAB with electrochemistry.

$\checkmark$ Applications of MATLAB in electrochemistry has been classified.

$\checkmark$ According to the number of selected papers applications of MATLAB were introduced.

$\checkmark$ The results were summarized and concluded. 


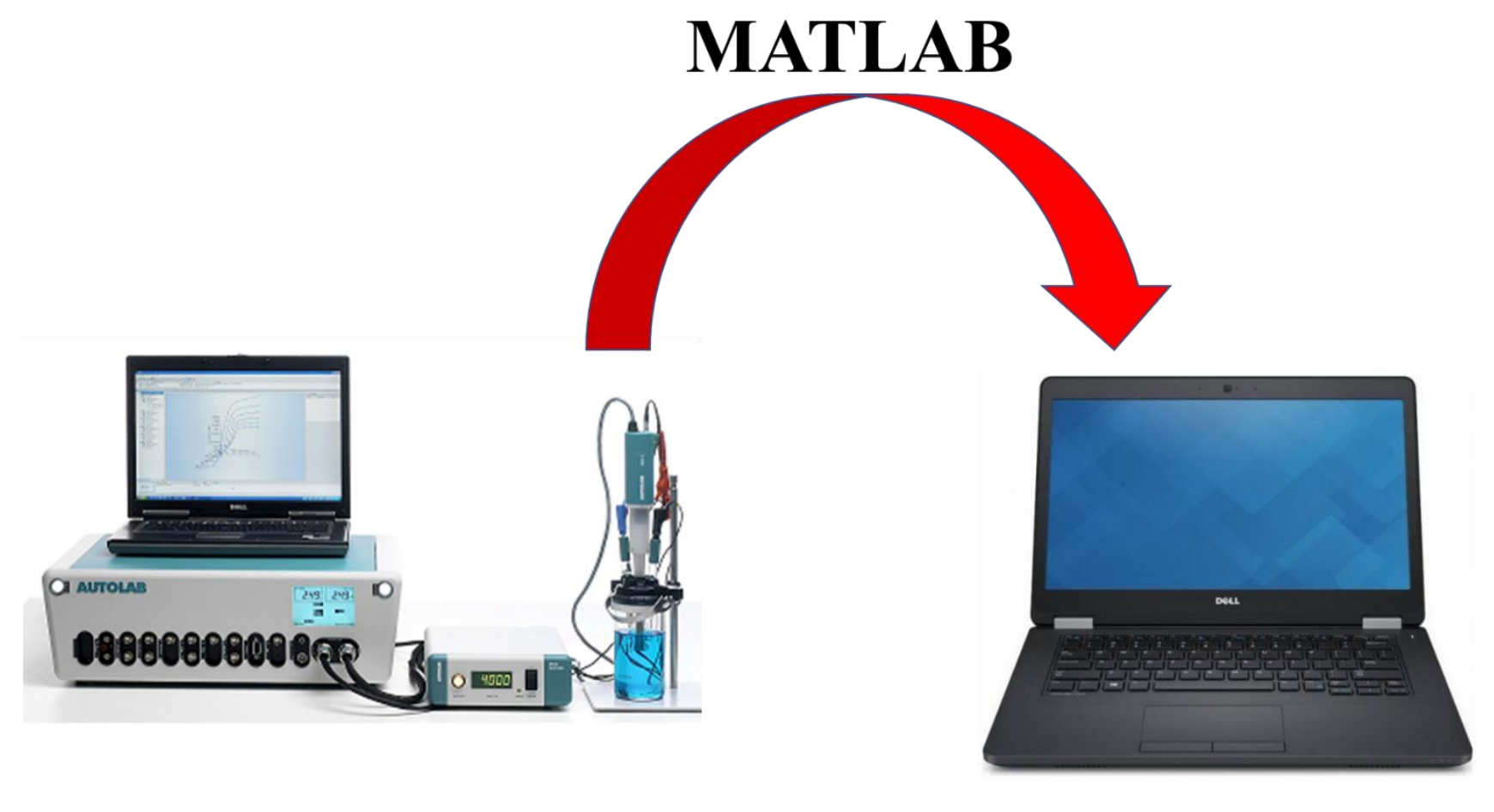

MATTLAAB 
1

\title{
MATLAB in Electrochemistry: A review
}

\author{
Ali R. Jalalvand ${ }^{\mathrm{a}, *}$, Farid Najafi $^{\mathrm{b}}$, Hector C. Goicoechea ${ }^{\mathrm{c}}$, Douglas N. Rutledge ${ }^{\mathrm{d}}$, Hui-Wen Gu ${ }^{\mathrm{e}}$ \\ ${ }^{a}$ Research Center of Oils and Fats, Kermanshah University of Medical Sciences, Kermanshah, Iran \\ ${ }^{\mathrm{b}}$ Research Center for Environmental Determinants of Health (RCEDH), School of Public Health, Kermanshah University of \\ Medical Sciences, Kermanshah, Iran \\ ${ }^{\complement}$ Laboratorio de Desarrollo Analítico y Quimiometría (LADAQ), C_atedra de Química Analítica I, Universidad Nacional \\ del Litoral, Ciudad Universitaria, CC 242 (S3000ZAA), Santa Fe, Argentina \\ ${ }^{\mathrm{d}}$ UMR Genial, AgroParisTech, INRA, Universit_e Paris-Saclay, 91300 Massy, France \\ ${ }^{\mathrm{e}}$ College of Chemistry and Environmental Engineering, Yangtze University, Jingzhou 434023, China \\ *Corresponding Author: Tel.: +988334302345, Fax: +988334279745 \\ E-mail Address: ali.jalalvand1984@gmail.com (A.-R. Jalalvand)
}

\begin{abstract}
MATLAB (MATrix LABoratory) is a multi-paradigm numerical computing environment and fourth-generation programming language. MATLAB allows matrix manipulations, plotting of functions and data, implementation of algorithms, creation of user interfaces, and interfacing with programs written in other languages, including $\mathrm{C}, \mathrm{C}^{++}$, Java, Fortran and Python. Electrochemistry is a branch of chemistry that studies the relationship between electricity, as a measurable and quantitative phenomenon, and identifiable chemical change, with either electricity considered an outcome of a particular chemical change or vice versa. MATLAB has obtained a wide range of applications in different fields of science and electrochemists are also using it for solving their problems which help them to obtain more quantitative and qualitative information about systems under their studies. In this review, we are going to cast a look on different applications of MATLAB in electrochemistry and for each section, a number of selected articles published in the literature will be discussed and finally, the results will be summarized and concluded.
\end{abstract}

Keywords: MATLAB; Electrochemistry; Quantitative and qualitative information; Solving of problem. 


\section{Required information \\ 1.1. MATLAB \\ 1.1.1. What is MATLAB?}

MATLAB, an acronym for MATrix LABoratory, is a product of The MathWorks, Inc. of Natick, MA [1]. The MATLAB is a high-performance and powerful language for technical computing. It integrates computation, visualization, and programming in an easy-to-use environment where problems and solutions are expressed in familiar mathematical notation. Typical uses are included: math and computation, algorithm development, modeling, simulation and prototyping, data analysis, exploration and visualization, scientific and engineering graphics and application development such graphical user interface building.

The MATLAB is an interactive system whose basic data element is an array that does not require dimensioning. This allows the user to solve many technical computing problems, especially those with matrix and vector formulations, in a fraction of the time it would take to write a program in a scalar noninteractive language such as $\mathrm{C}$ or Fortran. The MATLAB was originally written to provide easy access to matrix software developed by the LINPACK and EISPACK projects. Today, MATLAB uses software developed by the LAPACK and ARPACK projects, which together represent the state-of-the-art in software for matrix computation. The MATLAB has evolved over a period of years with input from many users. In university environments, it is the standard instructional tool for introductory and advanced courses in mathematics, engineering, and science.

\subsubsection{MATLAB environment}

MATLAB a multi-panel window appears containing Command Window, Workspace, Current Directory, and Command History panels, among others. This, along with windows for the Editor/Debugger, Array Editor, Help Browser, etc., that can be invoked as needed, is the MATLAB environment [2].

\subsubsection{The M-files}

MATLAB allows writing two kinds of program files including scripts and functions. Script files are program files with .m extension. In these files, the user can write a series of commands which wants to execute together. 
Scripts do not accept inputs and do not return any outputs. They operate on data in the workspace. Functions files are also program files with .m extension. Functions can accept inputs and return outputs. Internal variables are local to the function. The user can use the MATLAB editor or any other text editor to create your .m files.

\subsubsection{Toolboxes of MATLAB}

MATLAB features a family of application-specific solutions called toolboxes. Very important to most users of MATLAB, toolboxes allow the user to learn and apply specialized technology. Toolboxes are comprehensive collections of MATLAB functions (M-files) that extend the MATLAB environment to solve particular classes of problems. Areas in which toolboxes are available include signal processing, control systems, neural networks, fuzzy logic, wavelets, simulation, and many others. But, in this review article, we are going to focus on those toolboxes which had been frequently used in electrochemical projects.

\subsubsection{The most frequently used toolboxes of MATLAB in electrochemical projects 1.1.5.1. PLS toolbox}

PLS Toolbox is a collection of essential and advanced chemometric routines that work within the MATLAB computational environment [3]. It contains the tools required by chemical engineers, analytical chemists and other scientists to explore their data and build predictive models. PLS Toolbox gets its name from the Partial Least Squares (PLS) regression method, which has become the standard calibration method in many chemical applications. Although PLS Toolbox has grown far beyond just PLS, the name has been retained for the sake of continuity. Originally released in 1991, the routines in PLS Toolbox grew out of the authors' research and applications and were refined for publication [3]. All of these routines were originally coded so that their usefulness for modeling and monitoring dynamic systems could be confirmed. Indeed, the techniques were found to be quite useful and it seemed that publication of the routines as a software package was the logical next step. The routines shared the basic theme of multivariate analysis, multivariate calibration and multivariate statistical process control. Over the years, the application areas have expanded along with the tool set. Particular emphasis has been placed on routines for use in analytical chemistry, especially spectroscopy, and on the development of multi-way tools for analysis of 3-way and higher arrays [3]. 


\subsubsection{Image processing toolbox}

An image may be defined as a two-dimensional function, $f(\mathrm{x}, \mathrm{y})$, where $x$ and $y$ are spatial (plane) coordinates, and the amplitude of $f$ at any pair of coordinates $(\mathrm{x}, \mathrm{y})$ is called the intensity or gray level of the image at that point. When $x, y$, and the amplitude values of $f$ are all finite, discrete quantities, we call the image a digital image [4]. The field of digital image processing refers to processing digital images by means of a digital computer. The MATLAB has an image processing toolbox which provides a comprehensive set of reference-standard algorithms for image processing, analysis, visualization, and algorithm development. The image processing toolbox enables the user to perform image segmentation, image enhancement, noise reduction, geometric transformations, image registration, and 3D image processing.

\subsubsection{Neural network toolbox}

Neural networks are composed of simple elements operating in parallel. These elements are inspired by biological nervous systems [5]. As in nature, the connections between elements largely determine the network function. A neural network is trained to perform a particular function by adjusting the values of the connections (weights) between elements. Typically, neural networks are adjusted, or trained, so that a particular input leads to a specific target output. Neural networks have been trained to perform complex functions in various fields, including pattern recognition, identification, classification, speech, vision, and control systems.

Neural networks can also be trained to solve problems that are difficult for conventional computers or human beings. The neural network toolbox emphasizes the use of neural network paradigms that build up to-or are themselves used in engineering, financial, and other practical applications [5].

\subsubsection{Toolbox for multivariate calibration techniques (TOMCAT)}

Daszykowski et al. developed a user-friendly graphical interface (GUI) for robust calibration with a collection of m-files, called TOMCAT (TOolbox for Multivariate Calibration Techniques) [6]. The GUI allows a user to apply the implemented methods in an easy way and it gives a straightforward possibility to visualize the obtained results. Several useful features such as interactive numbering of the displayed objects on a plot, viewing the 
content of the data, easy transfer of the data between the toolbox and the MATLAB workspace and vice versa, are also implemented. Among the implemented methods there are Principal Component Analysis (PCA) and its robust variant, Partial Least Squares, Continuum Power Regression, Partial Robust M-Regression, Robust Continuum Regression and Radial Basis Functions Partial Least Squares.

\subsubsection{The $N$-way toolbox}

Andersson et al. introduced a free toolbox for MATLAB for the analysis of multi-way data called "The N-way Toolbox for MATLAB" [7]. The $N$-way Toolbox for MATLAB is a collection of functions and algorithms for modelling multi-way data sets by a range of multilinear models. Several types of models are covered; canonical decomposition-parallel factor analysis (CANDECOMP-PARAFAC), multilinear partial least-squares regression (PLSR), generalised rank annihilation method (GRAM), direct trilinear decom- position (DTLD), and the class of Tucker models. Selected types of optional constraints have been built into the least-squares error minimization algorithms for CANDECOMP-PARAFAC and Tucker models; nonnegativity, unimodality, and orthogonality. Different constraints may be set up for the different modes. In addition to these constraints, the structure of the Tucker models can be forced to allow only selected factor interactions. Furthermore, three methods for core simplification by orthogonal rotations have been implemented. Most of the algorithms in the toolbox can handle any number of modes $(N \geq 2)$ in data.

\subsubsection{MVC1 Toolbox}

Multivariate calibration 1 (MVC1) is a MATLAB toolbox for implementing several different first-order calibration methodologies including net analyte preprocessing followed by classical least squares (NAP/CLS) [8], partial least squrares-1 (PLS-1) [9], principal component regression (PCR) [9], orthogonal signal correction followed by PLS (OSC/PLS) [10], net analyte preprocessing followed by PLS (NAP/PLS) [11], direct orthogonal signal correction followed by PLS (DOSC/PLS) [12], OSC followed by CLS (OSC/CLS) [11], DOSC followed by CLS (DOSC/CLS) [13], multilinear regression (MLR) [14] and stepwise multilinear regression (STEPW/MLR) [14] through easily managed graphical user interfaces which was developed by Olivieri et al. [15]. The toolbox accepts different input data formats (either arranged as matrices or vectors contained in raw 
data files or in already existing MATLAB variables) and incorporates many preprocessing algorithms in order to improve prediction capabilities. The development and validation of each model and its subsequent application to unknown samples are straightforward. Prediction results are produced along analytical figures of merit and standard errors calculated by uncertainty propagation. Moreover, the toolbox allows one to manually select working sensor regions, or to automatically find which region provides the minimum error. It also generates many different plots regarding model performance, including outliers detection, facilitating both model evaluation and interpretation.

\subsubsection{MVC2 Toolbox}

Multivariate Calibration 2 (MVC2) is an integrated chemometric toolbox for MATLAB which was developed by Olivieri et al. [16] in order to manage several different second-order multivariate calibration algorithms in an easy-to-use graphical interface environment. The toolbox can be applied to any type of data which are structured in matrix form for each sample, allowing for the efficient extraction of information concerning certain properties or analytes of interest from the multi-component space. The toolbox is a sequel of the already described MVC1 toolbox and the MULTIVAR Visual Basic program [17], both developed for handling first-order multivariate calibration methods. The calibration techniques included in the MVC2 toolbox can be divided in two relevant groups, namely those based on: 1) trilinear decomposition (TLD) or 2) residual bilinearization (RBL). The former group include parallel factor analysis (PARAFAC) [18], alternating trilinear decomposition (ATLD) [19], alternating penalty TLD (APTLD) [20], and self-weighted ATLD (SWATLD) [21]. For a review of the properties and applicability of the different algorithms, see ref. [22,23]. The second group of methods, based on residual bilinearization, comprise: 1) bilinear least-squares followed by RBL (BLLS/RBL) [24,25], 2) unfolded partial least-squares/RBL (U-PLS/RBL) [26,27], 3) multidimensional partial least-squares/RBL (N-PLS/RBL) $[28,29]$, and unfolded principal component analysis/RBL (U-PCA/RBL) [30]. The latter methodology has been devised in order to produce suitably preprocessed data from non-linear instrumental data, for further analysis using artificial neural networks [31,32]. Calculations and graphical outputs are conveniently managed in MVC2 
through GUI shells. The software does not require a highly experienced user, but a basic knowledge on the underlying methods is advisable in order to successfully interpret the results.

\subsubsection{MVC3 Toolbox}

Multivariate calibration 3 (MVC3) is a sequel of the already described MVC1 and MVC2 toolboxes which was developed by Olivieri et al. [33] to manage several different third-order multivariate calibration algorithms in an easy-to-use GUI environment. The third-order multivariate calibration techniques included in MVC3 can be divided in two relevant groups, namely those based on: (1) quadrilinear decomposition (QLD) or (2) residual trilinearization (RTL). The former group includes parallel factor analysis (PARAFAC) [34], alternating penalty QLD (APQLD) [35] and alternating weighted residual constraint QLD (AWRCQLD) [36]. The second group of methods, based on residual trilinearization, comprise: 1) trilinear least-squares followed by RTL (TLLS/RTL) [37], 2) unfolded partial least-squares/RTL (U-PLS/RTL) [37], 3) multidimensional partial least-squares/RTL (NPLS/RTL) [38], and unfolded principal component analysis/RTL (U-PCA/RTL) [39]. The latter methodology has been developed to produce test sample scores from nonlinear instrumental data, which are free from the contribution of interferences, for further analysis using artificial neural networks [39]. Calculations and graphical outputs are conveniently managed in MVC3 through GUI shells. The software does not require a highly experienced user, but a basic knowledge on the underlying methods is advisable in order to successfully interpret the results.

\subsubsection{Successive projections algorithm toolbox}

The research group of Araujo developed a MATLAB GUI for the successive projections algorithm (SPA) which is a variable selection technique aimed at reducing collinearity problems in multiple linear regression (MLR) modelling [40]. The interface also offers the possibility of pre-processing the data using Savitzky-Golay smoothing/differentiation and/or wavelet denoising. Sample selection routines for dividing the samples into calibration and validation sets are also implemented. At the end, prediction statistics (PRESS, RMSEP, SDV, 
BIAS and correlation coefficient) are calculated to evaluate the performance of the resulting MLR model. All these operations can be carried out by the user without the need for MATLAB programming skills.

\subsubsection{Least square support vector machine toolbox}

Least square support vector machine (LS-SVM) is a state-of-the-art statistical algorithm and is capable of learning in high-dimensional feature space with fewer training variables or samples [41,42]. SVM has the capability of dealing with linear and nonlinear multivariate calibration and resolving these problems in a relatively fast way. Support vectors $(\mathrm{SVs})$ were obtained by applying linear equations instead of quadratic programming problems. The details of LSSVM algorithm could be found in the literature $[43,44]$.

\subsubsection{Multivariate curve resolution-alternating least squares toolbox}

Multivariate curve resolution (MCR) is a widespread and powerful methodology for the analysis and modeling of chemical data in many different application fields, the most prominent being process monitoring. This methodology provides a bilinear description of the observed data variation which is kept within the borders of the chemical realm through the implementation of adequate constraints. Multivariate resolution encompasses in its wider definition all the methods that aim at the decomposition of a data matrix into a linear model of dyads (the bilinear model). Currently, the most popular and flexible MCR algorithm is undoubtedly multivariate curve resolution-alternating least squares (MCR-ALS), proposed by Tauler in 1995 [45]. The MCR-ALS has become a popular chemometric method used for the resolution of multiple component responses in unknown and unresolved mixtures [46]. On one hand, this recognition is due to the great variety of data sets that can be analyzed by MCR methods; essentially, any multi-component system that gives as a result data tables or data matrices that can be described by a bilinear model $[46,47]$. This description includes all kinds of processes and mixtures monitored by diverse multivariate responses, such electrochemical measurements. On the other hand, other reasons for the acceptance of MCR-ALS are its ability to deal with multiple data matrices simultaneously (reducing factor analysis intrinsic ambiguities $[45,48,49]$ and/or data rank deficiencies [50,51]) and the diversity and flexible application of constraints to help and improve the resolution results. 
The MCR-ALS was originally developed by Tauler for spectroscopic data (obeys Beer's law) and it was shown to be a very powerful chemometric tool for spectroscopic studies. Later, the method was applied for voltammetric studies, and some modifications were introduced in order to adapt it to the characteristics of voltammetric data [52]. The conditions for the application of MCR-ALS to voltammetric data can be summarized as: (a) experimental currents must be measured at equally spaced potentials that are always identical, and (b) the currents should be linearly dependent on the concentration of the electroactive species present in the investigated system. In order to obtain high-quality data, the voltammograms used for data treatment should ideally correspond to the average of several consecutive experimental curves obtained using different electrodes. Moreover, a point-by-point subtraction of the background current (obtained for supporting electrolyte) from the total currents obtained in the presence of the studied system must be performed. This charging current subtraction assumes that the electrode double-layer capacitance does not change greatly in the presence of the test compound. Furthermore, a new interpretation about the concept of component in MCR-ALS must be applied to electrochemical data in relation to the concept as used with spectroscopic data [53]. This conceptual difference is crucial for the interpretation of MCR-ALS results from electrochemical data. The concept of component is a critical point, for spectroscopic data component is associated to pure chemical species in solution [48,54], but for electrochemical data component must be associated to a single electrochemical process giving a signal, including not only redox processes but also some other possible phenomena like, for instance, electrode adsorption of a species $[52,55]$ or capacitive currents due to the charging of the electrical double layer at the electrode surface. Anyway, in many situations, a single electrochemical process is produced by a single species. The number of components of each submatrix can be evaluated by singular value decomposition (SVD) [52,55]. Although this tool can be only considered as a guide since sometimes a component could be neglected if its concentration profile or its response vector is a lineal combination of others. Another issue with electrochemical data is the distinctive response (peak shape) of electrochemical methods (voltammetric methods) to every species which needs applying the signal-shape constrain, introduced for MCR-ALS of voltammetric data [53], that restricts pure signals to the expected peak shape by fitting it to a proper parametric equation, e.g. asymmetric logistic peak or 
logistic power peak. Comparative studies with different voltammetric techniques [56] have shown that the best results with MCR-ALS are obtained with peak-shaped signals (as compared with sigmoidal-shaped ones) with practically equal baselines at both sides of the peaks. As mentioned before, the main premise of MCR-ALS is to follow the multicomponent Beer's law. Consequently, it can be used to analyze the bilinear data and applying it to resolve data requires the uniform presentation of data, i.e., all signals have to be adjusted to the same length and corresponding variables have to be placed into the proper columns of the data matrix. The signals obtained from voltammetric techniques often do not fulfill this requirement. This problem is seen as the potential shift in electrochemical data. These facts cause a decrease in the linearity, which depends on the magnitude of the potential shift. In many cases, large lack of fit (lof) values are obtained and impel the analyst to use a higher number of components to explain the non-linearity.

\subsubsection{MCR-BANDS toolbox}

MCR-BANDS is a user friendly graphical interface and a command line MATLAB computer program for the evaluation of the extent of rotation ambiguities associated to MCR solutions [57]. The program allows for an easy check of the extent of rotation ambiguity remaining in MCR solutions in the investigation of a particular system and it also allows for the checking of the effect of applied constraints. In this way, conditions and limitations to achieve optimal solutions in MCR are easily assessed.

\subsubsection{3. shiftfit, $p H f i t, G P A, G P A 2 D$, and ALPA toolboxes}

The shiftit corrects the data matrix from signal movements and for this purpose, it optimises by least squares the potential shift of every pure voltammogram with respect to a reference position. To correct the potential shift, there are three MATLAB functions including peakmaker, shiftcalc and shiftfit. Peakmaker is a function that generates a Gaussian peak as an initial estimation of the pure voltammograms. The shiftcalc function displaces every signal in every experimental voltammograms matrix for a given potential shift $\Delta E$. The shifffit function iteratively optimizes the values of $\Delta E$ to generate a matrix $\left(I_{\mathrm{cor}}\right)$ in which all signals remain at the fixed potentials stated in the pure voltammograms matrix $\left(V_{\mathrm{o}}\right)[58,59]$. 
The $p H f i t$ algorithm can solve more intricate systems like those encountered in voltammetric $\mathrm{pH}$ titrations by imposing a shape restriction to the movements of the signals as a function of potential, by means of adjustable sigmoid or linear functions [60]. Both shiftfit and pHfit strategies could be used with any type of shape: the only restriction is that the pure signals of all components must remain unchanged along the whole experiment except for the height and the x-axis position, which are adjusted by the program. Nevertheless, losses of electrochemical reversibility, which are among the most usual non-linearity sources in voltammetric data, can dramatically affect the performance of both shiftfit and pHfit algorithms. The reason for that is the progressive broadening (and even the changes in peak symmetry) which take place as the electrochemical process becomes more irreversible. The mentioned algorithms could compensate the potential shift of pure signals whose shape remains unchanged, but they cannot cope with signals continuously changing their width and symmetry.

After shiftfit and pHfit, the Gaussian Peak Adjustment (GPA) algorithm based on a new strategy, parametric signal fitting (PSF), was proposed for the chemometric analysis of voltammetric data when the pure signals do not maintain a constant shape [61]. This is based on the fitting of parametric functions to reproduce the shape of the signals. As a first approach, two Gaussian functions are fitted, one at each side of the signal, and the parameters are least-squares optimised. Such parameters determine not only the height and position of the signals (as in the algorithms above), but also the width at both sides of the maximum. It is important to note that, unlike shiftfit and pHfit, the use of Gaussian functions restrict the GPA exclusively to peak-shaped signals. Moreover, it must be remarked that, despite fitting of Gaussian peaks has been already used in some situations such as the resolution of UV-vis spectra, in such approaches the symmetric character of the Gaussian function prevents an appropriate treatment of asymmetric signals. In the proposed method, the use of two separated Gaussian functions at both sides of the maximum (sharing the same height and position but different widths) is a new and simple solution for the fitting of asymmetric peaks. Fig. 1 summarizes the main steps of the fitting procedure.

\section{Figure 1}

A new method, GPA2D, was developed as a significant improvement of the GPA which includes, for the first time, transversal constraints to increase the consistency of the resolution along the different signals of a 
voltammetric dataset [62]. The aim of GPA2D is to extract a physicochemical sense to the evolution of the signals and their shifts along the experimental axis. The imposition of the transversal constraints makes this method more powerful for the analysis of voltammetric data, especially if they are non-bilinear. Fig. 2 shows the main structure of the operation program, which is based on a common GPA procedure with two alternative intermediate paths depending on the kind of transversal constraint to be applied (signal shift evolution or equilibrium).

\section{Figure 2}

The asymmetric logistic peak adjustment (ALPA) was developed as a new function for the PSF of highly asymmetric electrochemical signals in non-bilinear datasets or in the presence of irreversible electrochemical processes [63]. Fig. 3 summarizes the main steps of the fitting procedure.

\subsubsection{Correlation optimized warping (COW)}

\section{Figure 3}

The correlation optimized warping (COW) algorithm is also based on a piece-wise linear correction function and it is continuous and made up of segments whose slope is allowed to take a limited number of discrete values determined by the length $\ell$ of the interval in which the voltammograms are divided and the maximum number of scan points, s, by which the length of each interval is allowed to change $[64,65]$. When the slope of a segment of the correction function $f\left(t_{\mathrm{y}}\right)$ is not one, the corresponding intervals in sample and target contain a different number of points and linear interpolation is used so that the interval in the sample is compressed or expanded to the same length as the corresponding interval in the target. The optimized cost function is the sum of the Pearson's correlation coefficient for all segments after interpolation and Dynamic Programming is used to attain the global maximum given the constraints. Typically, a maximum allowed correction is set to further reduce the feasible region for $f\left(t_{\mathrm{y}}\right)$. One known problem of the standard COW method is that, close to the endpoints, the maximum correction allowed by the slope constraints is reduced. While it is possible to modify the algorithm to account for this, a computationally more intensive but equally effective solution is to attach zeroes at both ends of the signals so that the necessary flexibility is guaranteed (namely $w_{\max } \ell \mathrm{s}^{-1}$ zeroes should be attached at each end). 
It is worth mentioning, that, while COW also allows for custom intervals, here its commonest format is used in which sample and target are divided in segments of equal length.

\subsubsection{Interval correlation optimised shifting (icoshift)}

The interval correlation optimised shifting (icoshift) programme allows for different ways of aligning signals primarily due to different NMR alignment procedures [66]. The most relevant to voltammetry uses a piece-wise linear correction function based on an insertion/deletion (I/D) model [65]. In this method, one or more intervals are defined, either manually or automatically, on the potential axis and the segments in the sample to be aligned are shifted in order to maximize their cross-correlation with the corresponding segment of the target. The local maximum cross correlation upon shift is calculated using a Fast Fourier Transform (FFT) computation engine in which the optimal correction for all the samples is computed together and it is possible to fill in the inserted part using missing values [65]. Compared with other FFT based alignment methods (e.g., peak alignment by FFT (PAFFT) and recursive alignment by FFT (RAFFT)), endpoint contamination during the calculation of cross correlation (aliasing) is avoided by padding the segments with a number of zeroes corresponding to the maximum allowed correction $w_{\max }$ and improved efficiency is obtained by treating all the samples at once [65]. The icoshift only implements simple segmentation strategies, e.g., one can define a number of segments of equal length, but accepts interval definitions provided by the user, as is the case here. icoshift uses a greedy algorithm for the optimization [65], which means that the intervals are optimized separately, without accounting for any global effects. Note that, like other alignment methods but unlike COW, the icoshift optimization criterion is not well defined mathematically unless missing values are used for the insertion, because the cross-correlation function is not calculated after the correction is applied and the segment boundary point replicated. With respect to $w_{\max }$, it is possible to let icoshift automatically increase it, for each interval separately, if the optimal shift for any of the signals is found to be exactly on the boundary of the interim $w_{\max }$ value. The iterative procedure starts at $5 \%$ of the segment length and increases by an additional 5\% at each iteration, up to 50\% of the segment length. The icoshift programme has the built-in option of automatically picking the signal with the largest area under the 
curve as a target for each interval. This option was tested against the more standard approach of using as a single target either the average voltammogram or a representative sample with average potential shift.

\subsection{Electrochemistry}

Electrochemistry is a branch of chemistry concerned with the interrelation of electrical and chemical effects. A large part of this field deals with the study of chemical changes caused by the passage of an electric current and the production of electrical energy by chemical reactions [67]. In fact, the field of electrochemistry encompasses a huge array of different phenomena (e.g., electrophoresis and corrosion), devices (electrochromic displays, electroanalytical sensors, batteries, and fuel cells), and technologies (the electroplating of metals and the largescale production of aluminum and chlorine). Electroanalytical methods are a class of electrochemical techniques in analytical chemistry which study an analyte by measuring the potential or current in an electrochemical cell containing the analyte [68-71]. In general, it is well-known that electrochemical analysis has benefited from the electronics revolution in at least two important ways (i) the development of neater, faster, more simple and arguably, competitively affordable instrumentation, and (ii) the potential for rapid analysis. In addition, electrochemistry is a very versatile science offering the analyst a wide range of methods for analysis, e.g., coulometry, potentiometry, polarography and voltammetry, many of which are often available on the same instrument, and together provide optimum analytical solutions over a wide concentration range generally from ppb to $\mathrm{mg} \mathrm{L}^{-1}$ levels.

\subsection{Chemometrics}

Chemometrics is a chemical discipline that uses mathematics, statistics, and formal logic: (a) to design or to select optimal experimental procedures; (b) to provide maximum relevant chemical information by analyzing chemical data; and, (c) to obtain knowledge about chemical systems [72]. Chemometric analysis has gained widespread acceptance over the past two decades, responding to the need to study increasingly complex samples by improving existing analytical protocols. There is intensive research devoted to the development and the testing of multivariate algorithms applied to progressively more difficult chemical scenarios [73-76].

\subsection{Nomenclature for data, sample constituents and calibration 1.4.1. Data}




\subsubsection{Zeroth-order data}

Zeroth order corresponds to instruments producing a single response per sample (a zeroth-order tensor), such as the current at a single potential or the reading of an Autolab instrument [77]. When zeroth-order data for a group of samples are joined into a single, a vector is produced. Hence, zeroth-order data are also known as one-way data. Fig. 4 shows the natural progression from zeroth-order data as the simplest data to higher-order data.

\subsubsection{First-order data}

Figure 4

First-order data for a given sample are arranged as a vector or first-order tensor (Fig. 4), such as a voltammogram or chronoamperogram [77]. When first-order data for a group of samples are joined into a single, a matrix is produced. Hence, first-order data are also known as two-way data.

\subsubsection{Second-order data}

A data matrix for a single sample are considered to be second-order (Fig. 4) [77]. They can be recorded in two ways: (1) using a single instrument (e.g., such as an Autolab registering current-potential matrices at different pulse heights or pulse times); or, (2) coupling two "hyphenated" first-order instruments such as gas chromatography-mass spectrometry. When second-order data for a group of samples are joined into a single, three-dimensional array, the resulting object is known as three-way array. Hence, second-order data are also known as three-way data.

\subsubsection{Third-order data}

Introducing an extra dimension in the data leads to higher-order data, in which case the mathematical object obtained by grouping third-order data for several samples into the fourth dimension is known as a four-way array [77].

\subsubsection{Linearity and non-linearity of the data}

There is much confusion about the terms linear and linearity. Suppose a model is needed for relating $x_{\mathrm{i}}$ (the predictor) to $y_{\mathrm{i}}$ (the predictand), where $i$ indexes the objects and runs from 1 to $I$. Such a model is linear in the parameters and in the variables if it can be written as [78]:

$$
y_{i}=b_{0}+b_{1} x_{i}+e_{i} ; \quad i=1, \ldots, I
$$


which is the usual linear regression model with an intercept $\left(b_{0}\right)$ and an error term $\left(\varepsilon_{i}\right)$. An example of a model linear in the parameters but non-linear in $x$ is:

$$
y i=b_{0}+b_{1} x_{i}+b_{2} x_{i}^{2}+e_{i} ; \quad i=1, \ldots, I
$$

It is useful to distinguish these two types of linearity. If in the chemical sciences the term 'linearity' is loosely used, then often linearity in the parameters is meant. Hence, models in Eqs. (1) and (2) are linear in the parameters, because when $x$ is fixed, $y$ is a linear function of the parameters $b_{0}, b_{1}\left(\right.$ and $\left.b_{2}\right)$.

Non-linearity is a relationship which cannot be explained as a linear combination of its variable inputs. In other words, the outcome does not change in proportion to a change in any of the inputs.

Prior to selecting a linear or non-linear regression to fit the data for building a calibration model, it is important to know whether the signal varies linearly with analyte concentration or not. In next sections, different types of linearity a non-linearity will be discussed.

\subsection{Bilinearity versus non-bilinearity}

Bilinearity is a property assumed by multivariate linear calibration algorithms. This requires that a data matrix can be expressed as a sum of single component (analyte) data matrices, where each of them decomposes into the product of two vectors containing the concentrations and currents [79]. However, in many analytical situations, slight deviations from these assumptions have to be considered, such as, for example, in the presence of interactions between different individual components. In general, non-linearity of the signals results in the observation of strong signal shifts, peak broadening or non-proportional increase of the peak height. Any of these effects strongly hinder the direct application of bilinear data models. Such problems become more complicated when signals generated by successive analytes or interferences overlap [79].

\subsection{Trilinear data}

When second-order data are processed for a set of samples, it is important whether the three-dimensional array built with these data complies or not with the so-called trilinearity condition. The latter establishes that the threeway data array built with a set of second-order signals can be modeled through the following expression: 


$$
X_{i j k}=\sum_{i=1}^{N} a_{i n} b_{j n} c_{k n}+E_{i j k}
$$

where $N$ is the total number of chemical constituents generating the measured signal, $a_{\text {in }}$ is the relative concentration or score of component $n$ in the $i$-th sample, and $b_{\mathrm{jn}}$ and $c_{\mathrm{kn}}$ are the intensities in the instrumental channels (or data dimensions) $j$ and $k$, respectively. The values of $E_{\mathrm{ijk}}$ are the elements of the three-dimensional array $\mathbf{E}$, representing the residual error, and having the same dimensions as $\mathbf{X}$. The column vector $a_{\mathrm{n}}$ is collected in the scores matrix $\mathbf{A}$, while vectors $\boldsymbol{b}_{\mathrm{n}}$ and $\boldsymbol{c}_{\mathrm{n}}$ are collected in the loading matrices $\mathbf{B}$ and $\mathbf{C}$ (usually $\mathbf{b}_{\mathrm{n}}$ and $\mathbf{c}_{\mathrm{n}}$ are normalized to unit length). The above principle can be formulated in a less mathematical way. A threedimensional array will be trilinear provided the following requirements are verified: (1) the signal is linearly related to the analyte concentration; (2) the signal for a given sample is bilinear; and, (3) the component profiles are constant across the different samples. The first point simply means that the maximum signal, measured for a pure component at selected values of the sensors in each of the two data dimensions, is directly proportional to the component concentration. The second requirement implies that a single component data matrix can be decomposed into the product of two vectors, each containing the component profile in one of the two data dimensions. Finally, the third requirement implies that the shape of the profiles in all dimensions for a given component must be the same, with intensity variations being due only to different concentrations in different samples [80].

\subsection{Non-trilinear data}

To evaluate the linearity of a three-way data array should first consider its basic ingredients, i.e., the individual data matrices and whether they are bilinear or not. In case they are bilinear, a further subdivision can be made on the existence and number of trilinearity-breaking modes: (1) when one of the data modes is non-reproducible and breaks the trilinearity, the data are not trilinear, but can be unfolded into a bilinear augmented matrix, and (2) when both data modes are trilinearity breaking, the data are not trilinear and cannot be unfolded into a bilinear augmented matrix. To distinguish these two latter non-trilinear data types, we propose to call them non-trilinear Type 1 and non-trilinear Type 2, respectively. Finally, in case the individual matrices are non-bilinear, we have a fourth data type, which we may call non-trilinear Type 3. There is no point in further dividing Type 3 data 
according to the number of non-reproducible modes, since the former are neither trilinear nor unfoldable to an augmented bilinear matrix [77,80]. Fig. 5 illustrates the classification of three-way data for a sample set.

\subsection{Quadrilinear data}

\section{Figure 5}

Quadrilinearity of a four-way array can be defined by extension of Eq. (3), including an additional mode: the sample mode. A four-way data array obtained by "joining" three-dimensional data arrays for a sample set is quadrilinear if its elements can be thought to be obtained through:

$$
X_{i j k l}=\sum_{n=1}^{N} a_{i n} b_{j n} c_{k n} d_{1 \mathrm{n}}+E_{i j k l}
$$

where all symbols are as in Eq. (3), with $d_{\text {in }}$ describing the changes in constituent concentrations along the sample mode. A requirement for quadrilinearity of a data array for a sample set is that the three instrumental profiles for each constituent are equal for all samples [77].

\subsection{Non-quadrilinear data}

Quadrilinearity may be lost if one or more modes behave as quadrilinearity-breaking, in the sense that constituent profiles change from sample to sample along this mode. In the present case there might be one, two, or three quadrilinearity-breaking modes. Hence, a pertinent classification of non-quadrilinear third-order/four-way data would be in types 1,2, and 3 respectively. On the other hand, intrinsically non-trilinear data for each sample for reasons of mutual correlations among the phenomena in the different data modes will be classified as nonquadrilinear of type 4 [77]. Fig. 6 illustrates a classification tree.

\section{Figure 6}

\subsubsection{Generation of second- and third-order electrochemical data}

Differential pulse voltammetry (DPV) is the most frequently used technique for generation of second- and thirdorder electrochemical data. The second- or third-order data could be obtained via changing one or two of the instrumental parameters of DPV [81]. The theory behind the proposed procedure will be briefly discussed. The current signal intensity in DPV can be obtained using the following equations [82]:

$$
\mathrm{O}+\text { ne } \rightarrow \text { Red }
$$




$$
\begin{aligned}
& \delta_{i}=\frac{n F A D_{O}^{1 / 2} C_{O}^{*}}{\pi^{1 / 2}\left(\tau-\tau^{\prime}\right)^{1 / 2}}\left[\frac{P_{A}\left(1-\sigma^{2}\right)}{\left(\sigma+P_{A}\right)\left(1+P_{A} \sigma\right)}\right] \\
& P_{A}=\xi \exp \left[\frac{n F}{R T}\left(E+\frac{\Delta E}{2}-E^{0^{\prime}}\right)\right] \\
& \sigma=\exp \left(\frac{n F}{R T} \frac{\Delta E}{2}\right) \\
& \xi=\left(\frac{D_{O}}{D_{R e d}}\right)^{1 / 2}
\end{aligned}
$$

where $\mathrm{O}$ and Red are spices involved in the electrode reaction (Eq. (5)), $n$ is the number of electrons involved in the electrode reaction, $F$ is the faraday constant, $A$ is the electrode area, $D_{\mathrm{O}}$ and $D_{\mathrm{Red}}$ are diffusion coefficients of $\mathrm{O}$ and Red spices, respectively, $\mathrm{C}_{\mathrm{O}}^{*}$ is the concentration of $\mathrm{O}$ spices at the electrode surface, $R$ is gas constant, $T$ is temperature, $\Delta E$, $\mathrm{E}$ and $\mathrm{E}^{0^{\prime}}$ are pulse height, potential and formal potential of the electrode, respectively, $\tau$ and $\tau^{\prime}$ are, pulse duration or pulse time and starting time of potential pulse, respectively. For a typical electrochemical reaction, a data vector can be obtained by sweeping the potential at constant $\Delta E$ and $\tau$. Applying a different $\Delta E$ and sweeping potential at the constant $\tau$, will produce different data vectors, i.e., sweeping the potential and applying different $\Delta E$ at a constant $\tau$ in DPV produces a non-bilinear second-order data. By the same way, thirdorder voltammetric data could be obtained by sweeping potentials at different pulse heights and pulse durations [83]. Literature survey revealed that change of $\Delta E$ can cause non-linearity in the recorded DPV data while change of $\tau$ doesn't cause any non-linearity [81,84]. Therefore, it is reasonable to have a non-bilinear (change in $\Delta E$ ) and trilinear (change in $\tau$ ) three-way data array for each sample and finally a non-quadrilinear (change in concentration for sample to sample) four-way data array.

\subsubsection{Sample constituents}

It is important to define categories of sample constituents, focusing on those generating a signal that overlaps with the analyte of interest, as they can be considered as potential interferents. A distinction should first be made between constituents present in the calibration and validation sets of samples, and those that are present in only the unknown sample. The former can be called "expected" constituents, because they are included in the 
calibration and validation sets in order to ensure that they are sufficiently representative. However, truly unknown samples may contain additional constituents: the "unexpected". The expected constituents can be further divided into "calibrated" (referring to those for which calibration concentrations are available (including the analyte of interest)) and "uncalibrated" (referring to

constituents for which only a common subspace that contains them is accessible). Notice that potential interferents will not always produce an interference, in the sense of generating a systematic error in the analyte determination [85]. Whether the interference will be real or will remain as potential only depends on the type of instrumental signals and on the calibration methodology.

\subsubsection{Calibration}

According to the international union of pure and applied chemistry (IUPAC), calibration is, in a general sense, "an operation that relates an output quantity to an input quantity for a measuring system under given conditions" [86,77]. The input quantities of our primary interest, i.e., in analytical calibration, are the concentrations of a sample constituent of interest (the analyte), while the output quantities are analytical signals or responses delivered by analytical instruments (a spectrometer, chromatograph, voltammetric equipment, etc.). Therefore, in this review article calibration will mean the operation of relating instrumental signals to analyte concentrations.

\subsubsection{Univariate calibration}

A specific case of the general calibration process is the one relating the content of a single analyte in a sample to a single value of an instrumental signal, and is called "univariate calibration". In analytical chemistry, univariate calibration employs a calibration curve as a general method for the determination of the concentration of a constituent in an unknown sample [77].

\subsubsection{Multivariate calibration}

A more general calibration process involves the relationship between the concentrations of various constituents in a test sample and multiple measured responses, i.e., multivariate instead of univariate [77,87]. In contrast to univariate calibration, which works with a single instrumental response measured for each experimental sample, multivariate calibration works with many different signals for each sample. Depending on the instrumental setup, the delivered data for a single sample may have different degrees of complexity. The simplest multivariate data 


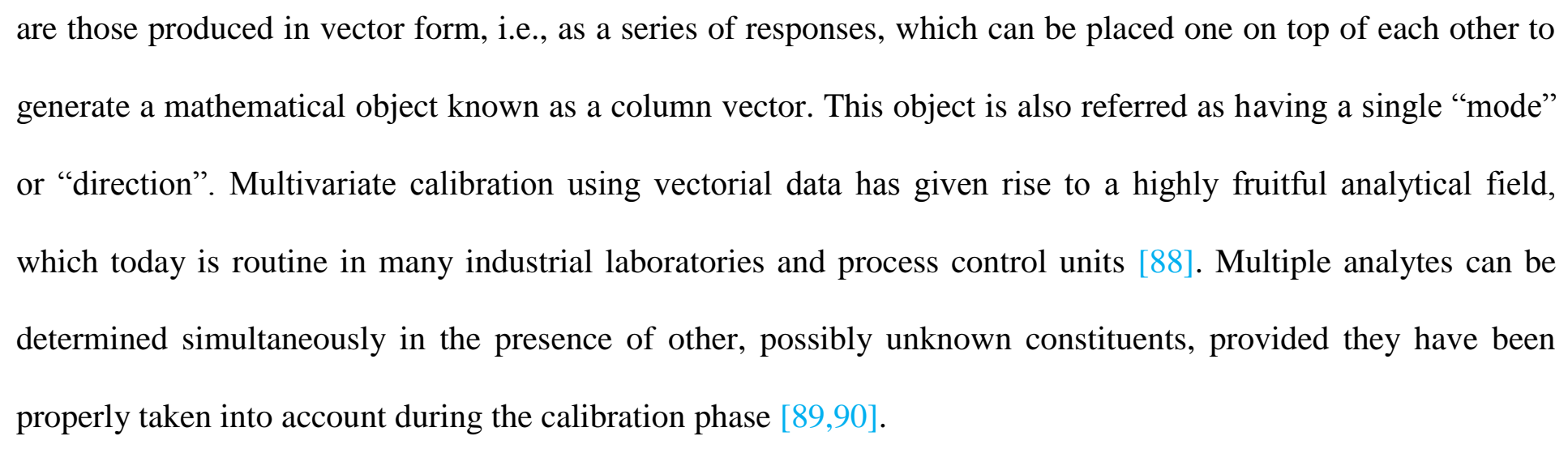

are those produced in vector form, i.e., as a series of responses, which can be placed one on top of each other to generate a mathematical object known as a column vector. This object is also referred as having a single "mode" or "direction". Multivariate calibration using vectorial data has given rise to a highly fruitful analytical field, which today is routine in many industrial laboratories and process control units [88]. Multiple analytes can be determined simultaneously in the presence of other, possibly unknown constituents, provided they have been properly taken into account during the calibration phase [89,90].

\subsubsection{Multi-way calibration}

Multi-way calibration is based on many instrumental signals per sample, which can be meaningfully organized into a certain mathematical object with more modes than a vector, for example, as a data table or matrix [77,78]. The most important advantage of multi-way calibration is the fact that analytes can be determined in the presence of unexpected constituents in test samples. It is called the "second-order advantage".

Multi-way calibration has interesting advantages relative to other calibration methods. One is the increase in sensitivity, because the measurement of redundant data tends to decrease the relative impact of the noise in the signal. Selectivity does also increase, because each new instrumental mode, which is added to the data contributes positively to the overall selectivity. Still another one is the possibility of obtaining qualitative interpretation of chemical phenomena through the study of multi-way data, in a much better way than with univariate or first-order data.

\section{Casting a look on applications of MATLAB in electrochemistry}

MATLAB is the most important program used by the chemometricians to solve their chemical problems. MATLAB can be linked with electrochemistry by the chemometricians and those electrochemists who are familiar with MATLAB-based chemometrical approaches. In electroanalytical projects, the sensor is usually modified with different materials to enhance the selectivity and sensitivity of the developed method [91-103], but the treatment involved is time-consuming and the associated cost is high. It is thus important to develop new 
methodologies. An attractive possibility is the coupling of chemometric approaches with electrochemical methods. This possibility have caused a lot of applications for MATLAB in electrochemical projects and we are going to cast a look on them in next sections.

\subsection{Improving the signal quality}

\subsubsection{Enhancing the sensitivity of electroanalytical methods}

In electroanalytical methods, many efforts have been made over the last several decades to enhance the sensitivity as a key parameter by improving the electrochemical signals [104-106].The double layer charging current, which is generated with the change of potential on the working electrode surface, causes interference with the accurate measurement of the faradaic current and restricts the detection limit $[107,108]$. Since the analytical signal is usually generated by changing the potential in most electrochemical techniques, it is inevitable to include the charging current in the measured signal of an electroanalytical system. Therefore, elimination of the charging current has been an important goal in electrochemical analysis. Applications of chemometrics methods such as MCR-ALS [109,110], iterative target transformation factor analysis (ITTFA) [111], and ATLD and PARAFAC $[112,113]$ for resolving net faradaic current contribution from total current have been reported. Safavi et al. have reported a work in which by using MCR-ALS as a powerful chemometrics method, a straightforward method has been introduced for resolving faradaic current from the two types of charging currents (step charging current and induced charging current) [109]. Cyclic voltammograms of a solution of 2.0 $\mathrm{mM} \mathrm{Co}(\text { phen })_{3} \mathrm{Cl}_{2}$ and $\mathrm{Ru}\left(\mathrm{NH}_{3}\right)_{6} \mathrm{Cl}_{3}$ in $0.1 \mathrm{M} \mathrm{KCl}$ at different scan rates are shown in Fig. 7. Figs. 8 and 9 show the application of the MCR-ALS to resolve different current types. As it is obvious from Figs. 8a and 9a, the net faradaic current cyclic voltammograms are very similar to the corresponding voltammograms of the raw data which are shown in Fig. 7. But, the values of current are about much larger than the corresponding values of raw data. This is because the induced charging current has negative contribution in total current and thus it suppress the observed faradaic current. Therefore, the pure faradaic component shows higher sensitivity rather than the raw cyclic voltammograms. Shao and Hemmateenejad who have the most important works on application of 
chemometrics to increase the sensitivity of electrochemical approaches have also performed more projects [110113].

Figure 7

Figure 8

Figure 9

\subsubsection{Data treatment}

\subsubsection{Baseline correction}

A variety of instruments deliver signals that consist of a series of more or less isolated peaks. The physical or chemical information is in the positions and the heights of the peaks. Ideally the baseline should be flat, but this is seldom the case. In practice slow, but strong, fluctuations are seen, which are known as background, drift, or baseline. Therefore, baseline correction has been considered as a critical step for enhancing the signals and reducing the complexity of the analytical data $[65,114]$. Considering this aim, Eilers et al. have introduced an algorithm for baseline elimination based on asymmetric least squares splines regression (AsLSSR) approach [115]. This algorithm is the most frequently used algorithm for baseline correction in electrochemical projects $[65,83,116-118]$.

\subsubsection{Potential shift correction}

Linearity is a property that is estimated by multivariate linear calibration algorithms. However, in many electroanalytical situations, slight deviations from linearity could be observed such as in the presence of interactions between different individual components. In general, nonlinearity of the signals results in the observation of strong signal shifts, peak broadening, or nonproportional increase in the peak height. Any of these effects strongly hinder the

direct application of linear data models. Such problems become more complicated when signals generated by successive analytes or interferences overlap. Therefore, the alignment of voltammograms is an important chemometric activity, which should be conducted before the application of multilinear data processing algorithms. The basis of these techniques involves digitally moving (and/or stretching or compressing) a voltammogram until it matches a reference one, with certain objective functions indicating the quality of the match (correlation coefficient, residual fit, similarity index, etc.). Some of the main differences among them are 
as follows: (1) whether alignment is performed using the continuous signal or individually detected peaks, (2) whether or not signal intensity is used, and (3) whether or not scale changes are corrected. The most important alignment methods that have been employed for aligning the voltammograms are COW, icoshift, GPA, GPA2D, ALPA, shiftfit and pHfit [58-63,65,83,116,117,119,120].

The work reported in Ref. [83] is interesting in which the raw DPV data (Fig. 10A) has been baseline corrected by AsLSSR (Fig. 10B) and then, the observed shift in the data has been corrected by the alignment of the data with help of COW as an efficient chemometric tool (Fig. 10C).

\subsection{Data exploration and sample classification}

Figure 10

There are some chemometric methods which are able to provide a way to visualize variation within large multivariate data sets as an end in itself or as a preprocessing step to discriminate information before building a classification model [121]. The PCA is the main tool for this purpose, and it can be implemented through a number of multivariate algorithms [121]. Some applications of chemometric methods to build classification models for screening different types of electrochemical data have been reported in the literature [122-150].

\subsection{Complexation}

Electrochemical methods can provide detailed information on processes taking place in solution because complexation or exchanging interactions can be gradually studied by changing the concentration of one component with respect to another. Polarographic and voltammetric techniques have been widely used to study the interactions between metal ions and a diversity of ligands [151-160]. These techniques can yield information about the physicochemical properties of the metal complexes. A major drawback of these techniques is the limited sensitivity which hinders the study at the low concentrations existing in natural media and anodic stripping voltammetry (ASV) seems to be a solution to this problem, but adsorption and especially the irreversible character of the reduction of metal complexes which does not produce the corresponding oxidation signals during the stripping step hinder its application [158]. Stripping chronopotentiometry (SCP) techniques appear as an alternative to voltammetry because it has been empirically proved to be less sensitive to the presence of important quantities of organic matter [161-167]. 
MCR-ALS as a soft modeling method plays a key role in metal-ligand complexation studies and for many systems high quality results were obtained by electrochemical data analyzed by MCR-ALS [158-160,167-172]. In an interesting work published by Chekmeneva et al. a novel electrochemical method based on DPV at a rotating Au-disk electrode was proposed to study binding of $\mathrm{Hg}^{2+}$ with several ligands by applying a previous deposition potential which allowed the adsorption of $\mathrm{Hg}^{2+}$ ions and/or their complexes on $\mathrm{Au}$ surface, followed by a cathodic potential scan [173]. The classical DPV scheme, without any preconcentration step, did not yield reproducible and reliable results. In order to reach additional information on the complexation processes, the MCR-ALS was used for data processing and interpretation, which permitted to obtain both the dynamic picture of complexation and stoichiometries of formed species. Fig. 11 shows the normalized individual voltammograms (a) and concentration profiles (b) obtained from MCR-ALS, with a lack of fit of 7.08\%. The constraints of nonnegativity, signal shape and selectivity were applied. Seven components were necessary for satisfactory completion of the data. The components I and II are related to $\mathrm{Hg}^{2+}$ reduction while the peak at $0.1 \mathrm{~V}$ does to the reduction of $\mathrm{Hg}^{2+}$ adsorbed on the electrode surface. The nature of component III appears to be very interesting. This type of signal is always observed with thiols at $\mathrm{Hg}$ electrodes, and it is of great importance because serves for determination of thiols. The component $\mathrm{V}$, which develops before the $\mathrm{Cys} / \mathrm{Hg}$ ratio of 1 and achieves the maximum at ratios close to 1 , seems to be related to a $1: 1 \mathrm{Hg}(\mathrm{Cys})$ complex. The component IV rises just after the profile of component $\mathrm{V}$ begins to descend (Fig. 11b). Moreover, it appears from the displacement of the peak described by component $\mathrm{V}$ towards more positive potential. They proposed that this could be due to the reorganization from one of the 1:1 complexes to another one, when increasing Cys concentration. Thereby, the signal displacement of component IV is observed and this peak persists until the end of the titration. The components VI and VII correspond to the signals appearing at very negative potentials. The component VI stabilizes at the Cys/Hg ratio of 1 , and it can be related to a 1:1 $\mathrm{Hg}$-Cys complex. Component VII achieves almost constant value at the ratio of 2 , and thus it is attributed to a stable 1:2 complex. Due to very negative potentials and the shape of these signals, they are related with reported phenomenon of cathodic reductive desorption of thiol-containing molecules from the Au-disk electrode. 


\section{Figure 11}

A great variety of complexation systems have also been investigated by different electroanalytical techniques and MCR-ALS [174-185].

\subsection{Small molecule-biomacromolecule interactions}

In general, there are many examples of complex reactions for which it is not only important to analyze the reactants but also the products. However, it can be quite difficult to analyze a multi-component reaction system, especially if one or more of the reaction species are complex. Typical illustrations of such systems are the interactions of small molecules with biomacromolecules such as DNA, human serum albumin (HSA) and bovine serum albumin (BSA), and it is often desirable to estimate simultaneously, the amounts of the small molecule, the biomacromolecule and their complex product. Such analytical tasks can be quite challenging, and composite profiles of the reactants and products are collected from instrumental analyses. Thus, the application of the common methods of data interpretation is often limited. However, chemometrics methods such as MCR-ALS, have provided a potential solution to resolve the analytical profile complexities. It is also possible, with the use of the expanded matrix methods [186], to combine data matrices of analyte profiles derived from different analytical methods [187]. In general, the results of such approaches have indicated that the increased information in the expanded matrix improves data analysis and subsequent interpretation of the results.

There are several reports on application of chemometric methods for resolving interactions of small molecules with biological macromolecules such as HSA, BSA and DNA [101,102,188-192]. I these studies, an augmented data matrix has been built by the combination of different spectroscopic and voltammetric data and then, the augmented data matrix has been resolved by MCR-ALS. The outputs of MCR-ALS had new information about small molecule-biomacromolecule interactions which helped the authors to better justify the interactions.

\subsection{Concentrations determination and calibration}

Calibration model building based on coupling of chemometric methods with electrochemical data for concentration determination includes first-, second- and third-order multivariate calibrations where the 
electrochemical data are processed by different algorithms and in this section, we are going to cast look on the works reported in the literature.

\subsubsection{First-order multivariate calibration}

The first-order multivariate calibration approach considers a series of experiments, e.g., the experimental data as a whole, without explicitly treating the individual signals, voltammogram by voltammogram [121]. For the most usual case of voltammetry, the fundamental starting point is the arrangement of the data as a matrix of currents $\mathbf{I}$ $(\mathrm{n} \mathbf{R}, \mathrm{nC})$, where $\mathrm{n} \mathbf{R}$ indicates the number of rows as the number of recorded voltammograms (of different samples, or of the same system but at some different conditions of any relevant variable), and $\mathrm{nC}$ indicates the number of columns, for example, potentials scanned during the current measurements [121]. The basic goal of the different multivariate analysis methods is to decompose mathematically the experimental current data matrix I into a product of two matrices (or vectors, depending on the case) containing the information of concentrations (C) and of the individual voltammograms (V). This decomposition is based on the assumption that the measured instrumental responses are bilinear and can be expressed as $\mathbf{I}=\mathbf{C V}+\mathbf{X}$, where $\mathbf{X}$ is a residual matrix containing the variance not explained by $\mathbf{C}$ and $\mathbf{V}$. The most popular first-algorithms which have been applied to electroanalytical data are including MLR, principal components regression (PCR), classical least squares (CLS), PLS, non-linear PLS and inverse least squares (ILS).

There are too many works which have been reported in the literature in which first-order electrochemical data have been used to build first-order multivariate calibration models. These works have been performed for food analyses [193-208], pharmaceutical and pesticide residues analyses [209-223] and environmental pollutant analyses [224-245]. Developing novel and efficient analytical methods based on coupling of first-order multivariate calibration with electrochemical data is very important from analytical point of view because such analyses are usually performed by UV-visible spectrophotometry, atomic absorption spectroscopy, inductively coupled plasma-mass spectrometry, X-ray fluorescence analysis, gas and liquid chromatography, near infra-red spectroscopy and mass spectrometry. However, these methods are accurate but are limited by time and cost while electrochemical methods such as voltammetry and polarography, are readily available for quantitative analyses. 
In most cases, the responses from such analyses overlap but these complex signals can be often resolved by the application of chemometrics.

\subsubsection{Multiway calibration}

Multi-way calibration increases the sensitivity due to the measurement of redundant data which decreases the relative impact of the noise in the data and selectivity is also increased because each new instrumental mode contributes positively to the overall selectivity [246,247]. Furthermore, multi-way calibration enables the analytical chemist to obtain more qualitative information about the chemical phenomena than with univariate or first-order data. Several techniques such as fluorescence excitation-emission [248], high performance liquid chromatography with diode array detection (HPLC-DAD) [249], liquid chromatography-attenuated total reflectance-Fourier transform infrared spectroscopy (LC-ATR-FTIR) [250], liquid chromatography-DAD-mass spectrometry (LC-DAD-MS) [251], flow injection analysis-DAD (FIA-DAD) [252], DAD-kinetics [253] and pH-DAD [254] have been used to obtain second-order data. Although these techniques are accurate and reliable but suffer from several disadvantages such as high-cost and complexity of their instruments. Therefore, new techniques are highly required for the inexpensive quantification of analytes in complex matrices. Among the available analytical methods, electrochemical methods with low-cost instruments and applicability to miniaturization are a good choice for accurate, fast and reliable determination of the analyte(s) of interest in interfering media. In this section, we are going to cast a look on applications of multi-way calibration in electrochemical analyses.

The use of multiway calibration in electrochemical analysis is still in its infancy and for many years, its application to electroanalytical data had been quite scarce as compared to the case of first-order multivariate calibration. There are some research groups which have been working on coupling of multiway calibration with electrochemical data and have performed interesting works [81,83,118,120, 255-265].

All the works published in the literature have been focused on the coupling of three-way calibration with second-order electrochemical data in which second-order advantage has been exploited for simultaneous determination of some analytes in the presence of uncalibrated interference. But, there is only one work which is 
related to coupling of four-way calibration with third-order electrochemical data [83]. In this work, a four-way multivariate calibration approach based on the combination of differential pulse voltammetric (DPV) data and four-way algorithms is described for the first time. To achieve this goal, the DPV response of each sample was recorded thirty-six times. Six current-potential matrices were recorded at six different pulse durations. Each matrix consists of six vectors which have been recorded at six different pulse heights. The three-way data array obtained for the calibration set and for each of the test samples were joined into a single four-way data array. The recorded four-way data array was nonlinear, thus, the non-linearities were tackled by potential shift correction using COW and subsequently was analyzed with U-PLS/RTL and N-PLS/RTL as third-order multivariate calibration algorithms. A comprehensive and systematic strategy for comparing the performance of the two algorithms was presented in this work, in particular with a view of practical applications. This comparison was developed to identify which algorithm offers the best predictions for the simultaneous determination of levodopa, carbidopa, methyldopa, acetaminophen, tramadol, lidocaine, tolperisone, ofloxacin, levofloxacin, and norfloxacin in the presence of benserazide, dopamine, and ciprofloxacin as uncalibrated interferences using a multi-walled carbon nanotubes modified glassy carbon electrode (GCE). This study demonstrated the more superiority of UPLS/RTL to resolve the complex systems. The results of applying U-PLS/RTL for the simultaneous determination of the studied analytes in human serum samples as experimental cases were also encouraging.

\subsection{Developing sensors and biosensors based on digital image processing}

Metallic nanoparticles (NPs) due to having high catalytic activity and catalytic selectivity are extensively used in fabrication of electrochemical sensors and biosensors. Their sizes are commonly linked directly to their catalytic activity, with different crystal nucleation and growth processes giving rise to different particle size distributions (PSDs). Therefore, estimation of PSD is an important parameter which must be statistically meaningful. Digital image processing (DIP) is an important which can be applied to determine PSD. Therefore, DIP can be used in fabrication of electrochemical sensors and biosensors. In a work published by Hezard et al., a GCE modified by Au NPs has been developed to $\mathrm{Hg}(\mathrm{II})$ trace analysis [266]. In this work, six GCEs have been modified by electrodeposition of Au NPs using cyclic voltammetry under applying different numbers of cyclic scans 
( $N=1,2,4,8,12$ and 16) and then, the images of the surfaces of the GCEs have been captured by field emission gun scanning electron microscopy (FEG-SEM). They have written a MATLAB code which can be applied to the FEG-SEM images for determination of NPs density and average diameter. Their results showed that the best performance has been observed for the GCE modified by 4 cyclic scan (the small-sized particles with high density). Finally, this modified GCE has been applied to the determination of $\mathrm{Hg}(\mathrm{II})$ with a linearity range from 0.64 to $4.00 \mathrm{nM}$ and a limit of detection of $0.42 \mathrm{nM}$.

Gholivand et al. have published a work on application of DIP in fabrication of a biotin biosensor [95]. In this work, nine GCEs modified by a room-temperature ionic liquid (RTIL)-chitin (Ch) composite film (PdFeNi/ChRTIL) were further modified by electrodeposition of PdFeNi trimetallic alloy NPs with help of cyclic voltammetry under applying different numbers of cyclic scans ( $\mathrm{N}=1,2,4,8,12,16,20,24$ and 28$)$. Then, the SEM images were captured from the surface of the modified electrodes which are showing in Fig. 12. Then, the images were analysed by a MATLAB code to obtain PSDs which are showing in Fig. 13. As can be seen, the best results were obtained for eight electrodeposition cyclic scans, where small-sized particles $(19.54 \pm 6.27 \mathrm{~nm})$ with high density $\left(682\right.$ particles $\mu \mathrm{m}^{-2}$ ) were obtained. Finally, the PdFeNi/ChRTIL/GCE was satisfactorily applied to the determination of biotin in infant milk powder, liver, and egg yolk samples.

Figure 12

Figure 13

\section{Conclusions}

The information collected in this review article confirmed that MATLAB is a powerful software which has a lot of applications in electrochemistry and electrochemists have used it for their qualitative and quantitative purposes. The works published in the literature showed that MATLAB could improve the quality of the electrochemical projects. MATLAB allows the electrochemists to write new algorithms which can help them to obtain more information about the systems under their study which can not be obtained by direct analysis of the electrochemical data. MATLAB has many toolboxes which have outstanding applications in different areas of electrochemistry such as complexation studies, separation of the faradic current contribution from total current to enhance the sensitivity of the electroanalytical 
techniques, calibration and concentration determination, small molecule-biomacromolecule interactions, improving the signal quality, data exploration and sample classification and digital image processing. The newest application of MATLAB in electrochemistry is using its digital image processing toolbox to explore the sensor surface to obtain a desirable and optimal surface for developing electrochemical sensors and biosensors. On the whole, this review was written from both electrochemical and chemometrical points of view with the aim of providing useful information for the electrochemists and to promote the use of MATLAB in electrochemistry.

\section{Acknowledgements}

The financial supports of this work by Research council of Kermanshah University of Medical Sciences are gratefully acknowledged.

\section{References}

[1] https://www.mathworks.com/.

[2] A. Gilat, MATLAB® an introduction with applications, John Wiley, New York, 2011.

[3] B.M. Wise, J.M. Shaver, N.B. Gallagher, W. Windig, R. Bro, R. Scott Koch, PLS_Toolbox 3.5 for use with MATLAB, Eigenvector Research, Inc., 830 Wapato Lake Road, Manson, WA 98831 USA, 2005.

[4] R.C. Gonzalez, R.E. Woods, Digital Image Processing, Prentice-Hall, New Jersey, 2002.

[5] M.H. Beale, M.T. Hagan, H.B. Demuth, Neural Network Toolbox ${ }^{\mathrm{TM}} 7$ User's Guide, The MathWorks, Inc., 2010 .

[6] M. Daszykowski, S. Serneels, K. Kaczmarek, P. Van Espen, C. Croux, B. Walczak, Chemom. Intell. Lab. Sys. 85 (2007) 269-277.

[7] Claus A. Andersson), Rasmus Bro, Chemom. Intell. Lab. Sys. 52 (2000) 1-4.

[8] H.C. Goicoechea, A.C. Olivieri, Trends Anal. Chem. 19 (2000) 599-605.

[9] D.M. Haaland, E.V. Thomas, Anal. Chem. 60 (1988) 1193-1202.

[10] T. Fearn, Chemom. Intell. Lab. Syst. 50 (2000) 47-52.

[11] H.C. Goicoechea, A.C. Olivieri, Chemom. Intell. Lab. Syst. 56 (2001) 73-81.

[12] J.A. Westerhuis, S. de Jong, A.K. Smilde, Chemom. Intell. Lab. Syst. 56 (2001) 13-25.

[13] D. Rodriguez, C.E. Boschetti, A.C. Olivieri, Analyst 127 (2002) 304-309.

[14] D.L. Massart, B.G.M. Vandeginste, L.M.C. Buydens, S. de Jong, P.J. Lewi, J. Verbeke, Handbook of Chemometrics and Qualimetrics (Parts A and B), Elsevier, Amsterdam, 1997.

[15] A.C. Olivieri, H.C. Goicoechea, F.A. Iñón, Chemom. Intell. Lab. Sys. 73 (2004) 189-197.

[16] A.C. Olivieri, H.L. Wu, R.Q. Yu, Chemom. Intell. Lab. Sys. 96 (2009) 246-251.

[17] H.C. Goicoechea, A.C. Olivieri, Trends Anal. Chem. 19 (2000) 599-605.

[18] R. Bro, Chemom. Intell. Lab. Syst. 38 (1997) 149-171.

[19] H.L. Wu, M. Shibukawa, K. Oguma, J. Chemom. 12 (1998) 1-26. 
[20] A.L. Xia, H.L. Wu, D.M. Fang, Y.J. Ding, L.Q. Hu, R.-Q. Yu, J. Chemom. 19 (2005) 65-76.

[21] Z-.P. Chen, H-.L.Wu, J-.H. Jiang, Y. Li, R.-Q. Yu, Chemom. Intell. Lab. Syst. 52 (2000) 75-86.

[22] G.M. Escandar, N.M. Faber, H.C. Goicoechea, A. Muñoz de la Peña, A.C. Olivieri, R.J. Poppi, Trends Anal. Chem. 26 (2007) 752-765.

[23] A.C. Olivieri, Anal. Chem. 80 (2008) 5713-5720.

[24] M. Linder, R. Sundberg, Chemom. Intell. Lab. Syst. 42 (1998) 159-178.

[25] H.C. Goicoechea, A.C. Olivieri, Appl. Spectrosc. 59 (2005) 926-933.

[26] J. Öhman, P. Geladi, S. Wold, J. Chemom. 4 (1990) 79-88.

[27] A.C. Olivieri, J. Chemom. 19 (2005) 253-265.

[28] R. Bro, J. Chemom. 10 (1996) 47-61.

[29] V.A. Lozano, G.A. Ibañez, A.C. Olivieri, Anal. Chim. Acta 610 (2008) 186-195.

[30] A.C. Olivieri, J. Chemom. 19 (2005) 615-624.

[31] M.J. Culzoni, P.C. Damiani, A. García-Reiriz, H.C. Goicoechea, A.C. Olivieri, Analyst 132 (2007) $654-663$. [32] A. García-Reiriz, P.C. Damiani, M.J. Culzoni, H.C. Goicoechea, A.C. Olivieri, Chemom. Intell. Lab. Syst. 92 (2008) 61-70.

[33] A. C. Olivieri, H.L. Wu c, R.Q. Yu, Chemom. Intell. Lab. Syst. 116 (2012) 9-16.

[34] R. Bro, Chemom. Intell. Lab. Syst. 38 (1997) 149-171.

[35] A.L. Xia, H.L. Wu, S.F. Li, S.H. Zhu, L.Q. Hu, R.Q. Yu, J. Chemom. 21 (2007) 133-144.

[36] H.Y. Fu, H.L. Wu, Y.J. Yu, L.L. Yu, S.R. Zhang, J.F. Nie, S.F. Li, R.Q. Yu, J. Chemom. 25 (2011) 408429.

[37] J.A. Arancibia, A.C. Olivieri, D. Bohoyo Gil, A. Muñoz de la Peña, I. Durán-Merás, A. Espinosa Mansilla, Chemom. Intell. Lab. Syst. 80 (2006) 77-86.

[38] P.C. Damiani, I. Durán Merás, A.G. García Reiriz, A. Jiménez Girón, A. Muñoz de la Peña, A.C. Olivieri, Anal. Chem. 76 (2007) 6949-6958.

[39] A.G. García Reiriz, P.C. Damiani, A.C. Olivieri, F. Cañada Cañada, A. Muñoz de la Peña, Anal. Chem. 80 (2008) 7248-7256.

[40] H. M. Paiva, S.F.C. Soares, R.K.H. Galvão, M.C.U. Araújo, Chemom. Intell. Lab. Syst. 118 (2012) 260266.

[41] J.A.K. Suykens, T. Van Gestel, J. De Brabanter, B. De Moor, J. Vandewalle, Least Squares Support Vector Machines, World Scientific, Singapore, 2002.

[42] J.A.K. Suykens, J. Vandewalle, Neural Process Lett. 9 (1999) 293-300.

[43] H. Guo, H.P. Liu, L. Wang, J. Syst. Simul. 18 (2006) 2033-2037.

[44] Q.S. Chen, J.W. Zhao, C.H. Fang, D.M. Wang, Spectrochim. Acta Pt. A 66 (2007) 568-574.

[45] R. Tauler, Chemome. Intell. Lab. Syst. 30 (1995) 133-146.

[46] J. Jaumot, R. Gargallo, A. de Juan, R. Tauler, Chemom. Intell. Lab. Syst. 76 (2005) 101-110.

[47] C. Ruckebusch, L. Blanchet, Anal. Chim. Acta 765 (2013) 28-36.

[48] R. Tauler, A.K. Smilde, B.J. Kowalski, J. Chemom. 9 (1995) 31-58.

[49] R. Tauler, J. Chemom. 15 (2001) 627-646.

[50] M. Amrhein, B. Srinivasan, D. Bonvin, M.M. Schumacher, Chemom. Intell. Lab. Syst. 33 (1996) 17-33.

[51] J. Saurina, S. Hernandez-Cassou, R. Tauler, A. Izquierdo-Ridorsa, J. Chemom. 12 (1998) 183-203.

[52] M. Esteban, C. Arino, J.M. Diaz-Cruz, M.S. Diaz-Cruz, R. Tauler, Trends Anal. Chem. 19 (2000) 49-61.

[53] A. Alberich, C. Arino, J.M. Diaz-Cruz, M. Esteban, Anal. Chim. Acta 584 (2007) 403-409.

[54] R. Tauler, A. Izquierdo-Ridorsa, E. Casassas, Chemome. Intell. Lab. Syst. 18 (1993) 293-300.

[55] M. Esteban, C. Arino, J.M. Diaz-Cruz, Trends Anal. Chem. 25 (2006) 86-92.

[56] J.M. Diaz-Cruz, R. Tauler, B.S. Grabaric, M. Esteban, E. Casassas, J. Electroanal. Chem. 393 (1995) 7-16.

[57] J. Jaumot, R. Tauler, MCR-BANDS: Chemome. Intell. Lab. Syst. 103 (2010) 96-107.

[58] A. Alberich, J.M. Diaz-Cruz, C. Arino, M. Esteban, Analyst, 133 (2008) 112-125.

[59] A. Alberich, J.M. Diaz-Cruz, C. Arino, M. Esteban, Analyst 133 (2008) 470-477.

[60] J.M. Diaz-Cruz, J. Sanchis, E. Chekmeneva, C. Arino, M. Esteban, Analyst 135 (2010) 1653-1662. 
[61] S. Cavanillas, J.M. Diaz-Cruz, C. Arino, M. Esteban, Anal. Chim. Acta 689 (2011) 198-205.

[62] S. Cavanillas, N. Serrano, J.M. Diaz-Cruz, C. Arino, M. Esteban, Analyst 138 (2013) 2171-2180.

[63] M. Kooshki, J.M. Diaz-Cruz, H. Abdollahi, C. Arino, M. Esteban, Analyst, 136 (2011) 4696-4703.

[64] G. Tomasi, F. Savorani, S.B. Engelsen, J. Chromatogr. A, 1218 (2011) 7832-7840.

[65] A.R. Jalalvand, M.B. Gholivand, H.C. Goicoechea, Å. Rinnan, T. Skov, Chemom. Intell. Lab. Syst. 146 (2015) 437-446.

[66] F. Savorani, G. Tomasi, S.B. Engelsen, J. Magn. Reson. 202 (2010) 190-202.

[67] A.J. Bard, L.R. Faulkner, Electrochemical Methods: Fundamentals and applications, John Wiley \& Sons, Inc., New York, 2001.

[68] J.C. Wang, Analytical electrochemistry, Chichester, Wiley, 2000.

[69] H.H. Girault, Analytical and physical electrochemistry, Lausanne, EPFL, 2004.

[70] K.I. Ozomwna, Recent advances in analytical electrochemistry, Transworld Research Network, 2007.

[71] E.A.M.F. Dahmen, Electroanalysis: theory and applications in aqueous and non-aqueous media and in automated chemical control, Amsterdam, Elsevier, 1986.

[72] D.L. Massart, B.G.M. Vandeginste, L.M.C. Buydens, S. De Jong, P.J. Lewi, J. Smeyers-Verbeke, Handbook of chemometrics and qualimetrics Part A, Amsterdam, Elsevier, 1998.

[73] G.M. Escandar, N.M. Faber, H.C. Goicoechea, A. Munoz de la Pena, A.C. Olivieri, R.J. Poppi, Trends Anal. Chem. 26 (2007) 752-765.

[74] R. Bro, Crit. Rev. Anal. Chem. 36 (2006) 279-293.

[75] A.C. Olivieri, Anal. Chem. 80 (2008) 5713-5720.

[76] K.S. Booksh, B.R. Kowalski, Anal. Chem. 66 (1994) 782-791.

[77] A.C. Olivieri, G.M. Escandar, Practical Three-way Calibration, Elsevier, Amsterdam, 2014.

[78] A. Smilde, R. Bro, P. Geladi, Multi-way Analysis with Applications in the Chemical Sciences, John Wiley \& Sons Ltd, 2004.

[79] M. Jakubowska, Ł. Gorski, R. Piech, Analyst, 138 (2013) 6817-6825.

[80] A.C. Olivieri, G.M. Escandar, A. Munoz de la Pena, Trends Anal. Chem. 30 (2011) 607-617.

[81] M. Kooshki, H. Abdollahi, S. Bozorgzadeh, B. Haghighi, Electrochim. Acta 56 (2011) 8618-8624.

[82] A.J. Bard, L.R. Faulkner, Electrochemical Methods: Fundamentals and Applications, John Wiley \& Sons, Inc., New York, 2001.

[83] A.R. Jalalvand, M.B. Gholivand, H.C. Goicoechea, Chemom. Intell. Lab. Syst. 148 (2015) 60-71.

[84] N.E. Llamas, M. Garrido, M.S.D. Nezio, B.S.F. Band, Anal. Chim. Acta 655 (2009) 38-42.

[85] W.E. Van der Linden, Pure Appl. Chem. 61 (1989) 91.

[86] https://en.wikipedia.org/wiki/Calibration.

[87] K. Danzer, L.A. Currie, Pure Appl. Chem. 70 (1998) 993-1014.

[88] D.A. Burns, E.W. Ciurczak. Handbook of near-infrared analysis in practical spectroscopy series, Boca Raton (USA), CRC Press, 2008.

[89] H. Martens, T. Næs, Multivariate calibration, Chichester, Wiley, 1989.

[90] D.L. Massart, B.G.M. Vandeginste, L.M.C. Buydens, S. De Jong, P.J. Lewi, J. Smeyers-Verbeke, Handbook of chemometrics and qualimetrics Part A, Amsterdam, Elsevier, 1998.

[91] K. Varmira, G. Mohammadi, M. Mahmoudi, R. Khodarahmi, K. Rashidi, M. Hedayati, H.C. Goicoecheae, A.R. Jalalvanda, Talanta 183 (2018) 1-10.

[92] K. Varmira, O. Abdi, M.B. Gholivand, H.C. Goicoechea, A.R. Jalalvand, Talanta 176C (2018) 509-517.

[93] A.R. Jalalvand, M.-B. Gholivand, H.C. Goicoechea, T. Skov, K. Mansouri, Int. J. Biol. Macromol. 79 (2015) 1004-1010.

[94] M.-B. Gholivand, A.R. Jalalvand, G. Paimard, H.C. Goicoechea, T. Skov, R. Farhadi, S. Ghobadi, N. Moradi, V. Nasirian, Int. J. Biol. Macromol. 70 (2014) 596-605.

[95] M.-B. Gholivand, A.R. Jalalvand, H.C. Goicoechea, G. Paimard, T. Skov, Talanta 131 (2015) 249-258.

[96] M.-B. Gholivand, A.R. Jalalvand, H.C. Goicoechea, Electrochim. Acta 133 (2014) 123-131.

[97] M.-B. Gholivand, A. R. Jalalvand, H.C. Goicoechea, Mater. Sci. Eng., C 40 (2014) 109-120. 
[98] M.-B. Gholivand, A.R. Jalalvand, H.C. Goicoechea, T. Skov, Talanta 124 (2014) 27-35.

[99] M.-B. Gholivand, A.R. Jalalvand, H.C. Goicoechea, Int. J. Biol. Macromol. 69 (2014) 369-381.

[100] M.-B. Gholivand, A.R. Jalalvand, H.C. Goicoechea, R. Gargallo, T. Skov, Talanta 132 (2015) 354-365.

[101] G. Mohammadi, E. Faramarzi, M. Mahmoudi, S. Ghobadi, A.R. Ghiasvand, H. C. Goicoechea, A.R. Jalalvand, J. Pharm. Biomed. Anal. 156 (2018) 23-35.

[102] A.R. Jalalvand, S. Ghobadi, H.C. Goicoechea, H.-W. Gu, E. Sanchooli, Bioelectrochemistry 123 (2018) $162-172$.

[103] A.R. Jalalvand, Talanta 188 (2018) 225-231.

[104] A. M. Bond, W. A. Czerwinski, M. Llorente, Analyst, 1998, 123, 1333-1337.

[105] A. Hermans, R. B. Keithley, J. M. Kita, L. A. Sombers, R. M. Wightman, Anal. Chem. 80 (2008) 40404048.

[106] K. Nisancioglu, J. Newman, J. Electrochem. Soc. 159 (2012) 59-61.

[107] L. H. L. Miaw, S. P. Perone, Anal. Chem. 51 (1979) 1645-1650.

[108] S. X. Guo, J. Zhang, D. M. Elton, A. M. Bond, Anal. Chem. 76 (2004) 166-177.

[109] A. Safavi, B. Hemmateenejad, F. Honarasa, Anal. Chim. Acta 766 (2013) 34-46.

[110] B. Hemmateenejad, A. Safavi, F. Honarasa, J. Electroanal. Chem. 755 (2015) 221-227.

[111] J. Tu, W. Cai, X. Shao, Talanta 116 (2013) 575-580.

[112] Jiarun Tu, Wensheng Cai, Xueguang Shao, J. Electroanal. Chem. 725 (2014) 25-31.

[113] J. Tu, W. Cai, X. Shao, Analyst 139 (2014) 1016-1022.

[114] M.M. De Zan, M.D. Gil García, M.J. Culzoni, R.G. Siano, H.C. Goicoechea, M. Martínez Galera, J. Chromatogr. A 1179 (2008) 106-114.

[115] P.H.C. Eilers, I.D. Currie, M. Durban, Comput. Statist. Data Anal. 50 (2006) 61-76.

[116] A.R. Jalalvand, H.C. Goicoechea, D.N. Rutledge, Trends Anal. Chem. 87 (2017) 32-48.

[117] A.R. Jalalvand, H.C. Goicoechea, Trends Anal. Chem. 88C (2017) 134-166.

[118] G. Mohammadi, K. Rashidi, M. Mahmoudi, H.C. Goicoechea, A.R. Jalalvand, J. Taiwan Inst. Chem. Eng. 88 (2018) 49-61.

[119] A.C. Silva, A.S. Lourenço, M.C.U. de Araujo, Food Chemistry 266 (2018) 232-239.

[120] M.-B. Gholivand, A.R. Jalalvand, H.C. Goicoechea, T. Skov, Talanta 134 (2015) 607-618.

[121] M. Esteban, C. Arino, and J. M. Diaz-Cruz, Crit. Rev. Anal. Chem. 36 (2006) 295-313.

[122] S. M. Rocha, S. Ganito, A. Barros, H. M. Carapuca, I. Delgadillo, Anal. Chim. Acta 528 (2005) 147-156.

[123] S. K. Schreyer and S. Mikkelsen, Sens. Actuators, B 71 (2000) 147-153.

[124] R. Bhattacharyya, B. Tudu, S.C. Das, N. Bhattacharyya, R. Bandyopadhyay, P. Pramanik, J. Food Eng. 109 (2012) 120-126.

[125] M. Ugliano, Food Chem. 212 (20160 837-843.

[126] F.F. Gambarra-Netoa, G. Marino, M.C.U. Araújo, R.K.H. Galvão, M.J.C. Pontes, Everaldo Paulo de Medeiros, Renato Sousa Lima, Talanta 77 (2009) 1660-1666.

[127] L. Francioso, R. Bjorklund, T. Krantz-Rulcker, P. Siciliano, Sens. Actuators, B 125 (2007) $462-467$.

[128] Æ. Górski, W. Sordoń, F. Ciepiela, W. W. Kubiak, M. Jakubowska, Talanta 146 (2016) 231-236.

[129] K. Stulik, Electroanalysis 11 (1999) 1001-1004.

[130] D. B. Hibbert, Electroanalysis 10 (1998) 1077-1080.

[131] S. Holmin, P. Spangeus, C. Krantz-R"ulcker, and F. Winquist, Sens. Actuators, B 76 (2001) 455-464.

[132] F. Winquist, P. Wide, I. Lundstrom, Anal. Chim. Acta 357 (1997) 21-31.

[133] F.Winquist, S. Holmin, C. Krantz-Rulcker, P.Wide, I. Lundstrom, Anal. Chim. Acta 406 (2000) 147-157.

[134] C. Krantz-Rulcker, M. Stenberg, F. Winquist, I. Lundstrom, Anal. Chim. Acta 426 (2001) 217-226.

[135] P. Ivarsson, S. Holmin, N. E. Hojer, C. Krantz-R"ulcker, F. Winquist, Sens. Actuators, B 76 (2001) 449454.

[136] F. Winquist, E. Rydberg, S. Holmin, C. Krantz-Rulcker, I. Lundstrom, Anal. Chim. Acta 471 (2002) 159172. 
[137] P. Ivarsson, M. Johansson, N. E. Hoejer, C. Krantz-Rulcker, F. Winquist, I. Lundstroem, Chem. Sens.20 (2004) 550-551.

[138] S. Holmin, C. Krantz-Rulcker, F. Winquist, Anal. Chim. Acta 519 (2004) 39-46.

[139] W. A. Collier, D. B. Baird, Z. A. Park-Ng, N. More, A. L. Hart, Sens. Actuators, B 92 (2003) 232-239.

[140] A. Carlsson, C. Krantz-R"ulcker, F. Winquist, Nord. Pulp. Pap. Res. J. 16 (2001) 319-326.

[141] H. Johnson, O. Karlsson, F. Winqvist, C. Krantz-R"ulcker, L. S. Ekedahl, Nord. Pulp. Pap. Res. J. 18 (2003) 134-140.

[142] C. Soderstrom, A. Rudnitskaya, A. Legin, C. Krantz-Rulcker, J. Biotechnol. 119 (2005) 300-308.

[143] T. A. Nguyen, S. Kokot, D. M. Ongarato, G. G. Wallace, Electroanalysis 11 (1999) 1327-1332.

[144] M. Wesoły, P. Ciosek-Skibińska, Sens. Actuators, B, 267 ( 2018 ) 570-580.

[145] M.G.N. Cruz, N.S. Ferreira, M.T.S.R. Gomes, M.J. Botelho, S.T.Costa, C. Vale, A. Rudnitskaya, Sens. Actuators, B, 263 (2018) 550-556.

[146] L. Sobrino-Gregorio, R. Bataller, J. Soto, I. Escriche, Food Control 91 (2018) 254-260.

[147] M. Wesoły, M. Zabadaj, A. Amelian, K. Winnicka, W. Wróblewski, P. Ciosek, Sens. Actuators, B, 238 (2017) 1190-1198.

[148] J.B. Lipkowitz, C.F. Ross, C. Diako, D.M. Smith, J. Dairy Sci. 101 (2018) 1990-2004.

[149] T.H. Borges, A.M. Peres, L.G. Dias, I. Seiquer, J.A. Pereira, LWT 93 (2018) 150-157.

[150] A. Rudnitskaya, L.M. Schmidtke, A. Reis, M. R.M. Domingues, I. Delgadillo, B. Debus, D. Kirsanov, A. Legin, Food Chem. 229 (2017) 20-27.

[151] J. Buffle, Complexation Reactions in Aquatic Systems: An Analytical Approach, Ellis Horwood, Chichester, 1988.

[152] M. Esteban, C. Arino, J.M. Diaz-Cruz, E. Casassas, Trends Anal. Chem. 12 (1993) 276-286.

[153] M.A.G.T. van den Hoop, H. P. van Leeuwen, Anal. Chim. Acta 273 (1993) 275-287.

[154] J.M. Diaz-Cruz, C. Arino, M. Esteban, E. Casassas, Anal. Chim. Acta 273 (1993) 289-296.

[155] C. Arino, A.M. Nadal, M. Esteban, E. Casassas, Electroanalysis 4 (1992) 757-764.

[156] B. Yosypchuk, I. Sestakova, L. Novotny, Talanta 59 (2003) 1253-1258.

[157] G. Scarano, E. Morelli, Anal. Chim. Acta 319 (1996) 13-18.

[158] N. Serrano, I. Sestakova, J.M. Diaz-Cruz, C. Arino, J. Electroanal. Chem. 591 (2006) 105-117.

[159] B.H. Cruz, J.M. Diaz-Cruz, I. Sestakova, J. Velek, C. Arino, M. Esteban, J. Electroanal. Chem. 520 (2002) 111-118.

[160] A. Alberich, J.M. Diaz-Cruz, C. Arino, M. Esteban, Analyst 133 (2008) 470-477.

[161] J.M. Estela, C. Tomas, A. Cladera, V. Cerda, Crit. Rev. Anal. Chem. 25 (1995) 91-141.

[162] D. Jagner, Analyst 107 (1982) 593-599.

[163] M.L. Gozzo, L. Colacicco, C. Calla, G. Barbaresi, R. Parroni, B. Giardina, S. Lippa, Clin. Chim. Acta 285 (1999) 53-68.

[164] R.M. Town, H.P. Van Leeuwen, J. Electroanal. Chem. 523 (2002) 1-15.

[165] R. Tauler, A. Izquierdo-Ridorsa, E. Casassas, Chemom. Intell. Lab. Syst. 18 (1993) 293-300.

[166] S.D. Brown, R.S. Bear Jr., Crit. Rev. Anal. Chem. 24 (1993) 99-131.

[167] R. Tauler, A. Izquierdo-Ridorsa, E. Casassas, Chemom. Intell. Lab. Syst. 18 (1993) 293-300.

[168] B.H. Cruz, J.M. Diaz-Cruz, C. Arino, M. Esteban, Environ. Sci. Technol. 39 (2005) 778-786.

[169] E. Chekmeneva, J.M. Diaz-Cruz, C. Arino, M. Esteban, Electroanalysis 19 (2007) 310-317.

[170] J.M. Diaz-Cruz, R. Tauler, B.S. Grabaric, M. Esteban, E. Casassas, J. Electroanal. Chem. 393 (1995) 7-16.

[171] B.H. Cruz, J.M. Diaz-Cruz, M.S. Diaz-Cruz, C. Arino, M. Esteban, R. Tauler, J. Electroanal. Chem. 516 (2002) 110-118.

[172] M. Fernandez, C. Arino, J.M. Diaz-Cruz, R. Tauler, M. Esteban, J. Electroanal. Chem. 505 (2001) 44-53.

[173] E. Chekmeneva, J.M. Diaz-Cruz, C. Arino, M. Esteban, J. Electroanal. Chem. 629 (2009) 169-179.

[174] V. Sosa, N. Serrano, C. Arino, J.M. Diaz-Cruz, M. Esteban, Talanta 107 (2013) 356-360.

[175] B. Hemmateenejad, A. Safavi, F. Honarasa, Anal. Methods 4 (2012) 1776-1782.

[176] A. Alberich, C. Arino, J.M. Diaz-Cruz, M. Esteban, Anal. Chim. Acta 584 (2007) 403-409. 
[177] K. Asadpour-Zeynali, J. Vallipour, Anal. Methods 2 (2010) 1969-1973.

[178] J.M. Diaz-Cruz, J. Sanchis, E. Chekmeneva, C. Arino, M. Esteban, Analyst 135 (2010) 1653-1662.

[179] R. Gusmao, C. Arino, J.M. Diaz-Cruz, M. Esteban, Analyst 135 (2010) 86-95.

[180] A. Alberich, J.M. Diaz-Cruz, C. Arino, M. Esteban, Analyst 133 (2008) 112-125.

[181] B.H. Cruz-Vasquez, J.M. Diaz-Cruz, C. Arino, M. Esteban, R. Tauler, Analyst 127 (2002) 401-406.

[182] S. Cavanillas, J.M. Diaz-Cruz, C. Arino, M. Esteban, Anal. Chim. Acta 689 (2011) 198-205.

[183] S. Cavanillas, N. Serrano, J.M. Diaz-Cruz, Cristina Arino, M. Esteban, Analyst 138 (2013) 2171-2180.

[184] C. Gilsanz, R. Gusmao, E. Chekmeneva, N. Serrano, J.M. Diaz-Cruz, C. Arino, M. Esteban, Electrochim. Acta 56 (2011) 5988-5992.

[185] N. Serrano, K. Klosova, L. Trnkova, Electroanalysis 22 (2010) 2071-2080.

[186] M. Vives, R. Gargallo, R. Tauler, Anal. Chim. Acta 424 (2000) 105-114.

[187] Y.N. Ni, Y.H. Lai, S. Brandes, S. Kokot, Anal. Chim. Acta 647 (2009) 149-158.

[188] M.B. Gholivand, A.R. Jalalvand, H.C. Goicoechea, R. Gargallo, T. Skov, Talanta 132 (2015) 354-365.

[189] M.B. Gholivand, A.R. Jalalvand, H.C. Goicoechea, M. Omidi, Spectrochim. Acta, Part A 115 (2013) 516527.

[190] M.B. Gholivand, A.R. Jalalvand, H.C. Goicoechea, Int. J. Biol. Macromol. 69 (2014) 369-381.

[191] Y. Ni, M. Wei, S. Kokot, Int. J. Biol. Macromol. 49 (2011) 622-628.

[192] Y. Ni, X Zhang, S. Kokot, Spectrochim. Acta, Part A, 71 (2009) 1865-1872.

[193] J. Saurina, S. Hernandez-Cassou, E. Fabregas, S. Alegret, Analyst 124 (1999) 733-737.

[194] J. Saurina, S. Hernandez-Cassou, E. Fabregas, S. Alegret, Anal. Chim. Acta 405 (2000) 153-160.

[195] A. Herrero, M.C. Ortiz, J. Electroanal. Chem. 432 (1997) 223-227.

[196] S.M. Rocha, S. Ganito, A. Barros, H.M. Carapuca, I. Delgadillo, Anal. Chim. Acta 528 (2005) 147-156.

[197] T.G. Diaz, A. Guiberteau Cabanillas, M.F.A. Franco, F. Salinas, J.C. Vire, Electroanalysis 10 (1998) $497-$ 505.

[198] Y.N. Ni, L. Wang, S. Kokot, Anal. Chim. Acta 412 (2000) 185-193.

[199] Y.N. Ni, J.L. Bai, L. Jin, Anal. Chim. Acta 329 (1996) 65-72.

[200] Y.N. Ni, J.L. Bai, L. Jin, Anal. Lett. 30 (1997) 1761-1777.

[201] P.L. Lopez-de-Alba, L. Lopez-Martinez, L.M. De-Leon-Rodriguez, Electroanalysis 14 (2002) 197-205.

[202] T.G. Diaz, A. Espinosa-Mansilla, B.R. Murillo, F. Salinas, Electroanalysis 13 (2003) 646-651.

[203] A.A. Ensafi, R. Hajian, Anal. Chim. Acta 580 (2006) 236-243.

[204] L. Moreno, A. Merkoci, S. Alegret, S. Hernandez-Cassou, J. Saurina, Anal. Chim. Acta 507 (2004) $247-$ 253.

[205] T.G. Diaz, I.D. Meras, A. Guiberteau Cabanillas, M.F.A. Franco, Anal. Chim. Acta 511 (2004) 231-238.

[206] S.K. Schreyer, S.R. Mikkelsen, Sens. Actuators B 71 (2000) 147-153.

[207] Y.N. Ni, S. Kokot, M. Selby, M. Hodgkinson, Analyst 118 (1993) 1049-1057.

[208] Y.N. Ni, S. Kokot, M. Selby, M. Hodgkinson, Anal. Chim. Acta 316 (1995) 233-238.

[209] J.M.G. Fraga, A.I.J. Abizanda, F.J. Moreno, J.J.A. Leon, Talanta 46 (1998) 75-82.

[210] S. Furlanetto, S. Pinzauti, P. Gratteri, E. La Porta, G. Calzeroni, J. Pharm. Biomed. Anal. 15 (1997) 15851594.

[211] J. Rojas, A.F. Tachon, D. Chevalier, T. Noguer, J.L. Marty, Ch. Ghommidh, Sens. Actuators B 102 (2004) 284-290.

[212] M.L.A.V. Heien, M.A. Johnson, R.M. Wightman, Anal. Chem. 76 (2004) 5697-5704.

[213] A. Navalon, R. Blanc, L. Reyes, N. Navas, J.L. Vilchez, Anal. Chim. Acta 454 (2002) 83-91.

[214] A.G. Cabanillas, T.G. Diaz, A. Espinosa-Mansilla, P.L. Lopez-de-Alba, F.S. Lopez, Anal. Chim. Acta 302 (1995) 9-19.

[215] R.C. Matos, L. Angnes, M.C.U. Araujo, T.C.B. Saldanha, Analyst 125 (2000) 2011-2015.

[216] F.B. Berbel, E. Kapoya, J.M. Diaz-Cruz, C. Arino, M. Esteban, R. Tauler, Electroanalysis 15 (2003) 499508.

[217] E. Cukrowska, L. Trnkova, R. Kizek, J. Havel, J. Electroanal. Chem. 503 (2001) 117-124. 
[218] C. Reguera, M.C. Ortiz, M.J. Arcos, Electroanalysis 14 (2002) 1699-1706.

[219] M.R. Majidi, A. Jouyban, K. Asadpour-Zeynali, Electroanalysis 17 (2005) 915-918.

[220] Y.N. Ni, Y.R. Wang, S. Kokot, Talanta 69 (2006) 216-225.

[221] Y.N. Ni, Y.R. Wang, S. Kokot, Anal. Lett. 37 (2004) 3219-3235.

[222] Y.N. Ni, L. Wang, S. Kokot, Anal. Chim. Acta 439 (2001) 159-168.

[223] A. Gutes, F. Cespedes, R. Cartas, S. Alegret, M. del Valle, J.M. Guitierrez, R. Munoz, Chemom. Intell. Lab. Syst. 83 (2006) 169-179.

[224] M.J.G. Gonzalez, O.D. Renedo, M.J.A. Martinez, Talanta 71 (2007) 691-698.

[225] M.S. Moneeb, Talanta 70 (2006) 1035-1043.

[226] S.X. Ren, L. Gao, J. Electroanal. Chem. 586 (2006) 23-30.

[227] M.J.G. Gonzalez, O.D. Renedo, M.J.A. Martinez, Electroanalysis 18 (2006) 1159-1166.

[228] A. Jaworski, K. Wikiel, H. Wikiel, Electroanalysis 17 (2005) 1477-1485.

[229] A. Herrero, M.C. Ortiz, Anal. Chim. Acta 348 (1997) 51-59.

[230] M.B. Sanz, L.A. Sarabia, A. Herrero, M.C. Ortiz, Electroanalysis 16 (2004) 748-756.

[231] A. Herrero, M.C. Ortiz, Electroanalysis 10 (1998) 717-721.

[232] L.A. Sarabia, M.C. Ortiz, M.J. Arcos, M.S. Sanchez, A. Herrero, S. Sanllorente, Chemom. Intell. Lab. Syst. 61 (2002) 89-104.

[233] M.C. Ortiz, J. Arcos, L. Sarabia, Chemom. Intell. Lab. Syst. 34 (1996) 245-262.

[234] A. Herrero, M.C. Ortiz, Talanta 49 (1999) 801-811.

[235] O. Dominguez, M.J. Arcos, Anal. Chim. Acta 470 (2002) 241-252.

[236] O. Dominguez, M.J. Arcos, Electroanalysis 12 (2000) 449-458.

[237] M.C. Antunes, J.E. Simao, A.D.C. Duarte, Electroanalysis 13 (2001) 1041-1045.

[238] A. Alpizar, A. Cladera, V. Cerda, E. Lastres, L. Garcia, M. Catasus, Anal. Chim. Acta 340 (1997) 149-158.

[239] J.E.T. Andersen, E.H. Hansen, Fresenius J. Anal. Chem. 362 (1998) 77-83.

[240] T. Khayamian, A.A. Ensafi, M. Atabati, Microchem. J. 65 (2000) 347-351.

[241] T. Khayamian, A.A. Ensafi, A. Benvidi, Talanta 69 (2006) 1176-1181.

[242] S.S. Khaloo, A.A. Ensafi, T. Khayamian, Talanta 71 (2007) 324-332.

[243] A.A. Ensafi, T. Khayamian, A. Benvidi, E. Mirmomtaz, Anal. Chim. Acta 561 (2006) 225-232.

[244] A.A. Ensafi, T. Khayamian, M. Atabati, Talanta 57 (2002) 785-793.

[245] Y.N. Ni, L. Jin, Chemom. Intell. Lab. Syst. 45 (1999) 105-111.

[246] A.C. Olivieri, Anal. Chem. 80 (2008) 5713-5720.

[247] J.A. Arancibia, P.C. Damiani, G.M. Escandar, G.A. Ibañez, A.C. Olivieri, J. Chromatogr. B, 910 (2012) 22-30.

[248] T. Madrakian, A. Afkhami, M. Mohammadnejad, Anal. Chim. Acta 645 (2009) 25-29.

[249] Y. Zhang, H.L. Wu, A.L. Xia, Q.J. Han, H. Cui, R.Q. Yu, Talanta 72 (2007) 926-931.

[250] A. Edelmann, J. Diewok, J.R. Baena, B. Lendl, Anal. Bioanal. Chem. 376 (2003) 92-97.

[251] E. Pere-Trepat, R. Tauler, J. Chromatogr. A 1131 (2006) 85-96.

[252] A. Checa, R. Oliver, J. Saurina, S. Hernandez-Cassou, Anal. Chim. Acta 572 (2006) 155-164.

[253] M.J. Culzoni, P.C. Damiani, A. Garcia-Reiriz, H.C. Goicoechea, A.C. Olivieri, Analyst 132 (2007) 654663.

[254] H.C. Goicoechea, A.C. Olivieri, Appl. Spectrosc. 59 (2005) 926-933.

[255] T. Galeano-Diaz, A. Guiberteau-Cabanillas, A. Espinosa-Mansilla, M.D. Lopez-Soto, Anal. Chim. Acta 618 (2008) 131-139.

[256] A. Khoobi, S.M. Ghoreishi, S. Masoum, M. Behpour, Bioelectrochemistry 94 (2013) 100-107.

[257] A. Khoobi, S.M. Ghoreishi, M. Behpour, S. Masoum, Anal. Chem. 86 (2014) 8967-8973.

[258] S.M. Ghoreishi, A. Khoobi, M. Behpour, S. Masoum, Electrochim. Acta 130 (2014) 271-278.

[259] S. Masoum, M. Behpour, F. Azimi, M.H. Motaghedifard, Sens. Actuat. B 193 (2014) 582-591.

[260] H. Keller, D. Massart, Anal. Chim. Acta 246 (1991) 379-390. 
[261] M. Meshki, M. Behpour, S. Masoum, J. Electroanal. Chem. 740 (2015) 1-7.

[262] N.M. Diez, A.G. Cabanillas, A.S. Rodríguez, H.C. Goicoechea, Talanta 132 (2015) 851-856.

[263] A.M. Granero, G.D. Pierini, S.N. Robledo, M. S. Di Nezio, H. Fernandez, M.A. Zon, Microchem. J., 129 (2016) 205-212.

[264] A. Jaworski, H. Wikiel, K. Wikiel, Electroanalysis, 21 (2009) 580-589.

[265] H. Abdollahi, M. Kooshki, Electroanalysis 22 (2010) 2245-2253.

[266] T. Hezard, K. Fajerwerg, D. Evrard, V. Collière, P. Behra, P. Gros, J. Electroanal. Chem. 664 (2012) $46-52$.

\section{Caption to figures:}

Fig. 1. Flowchart of the GPA [61].

Fig. 2. Flowchart of the GPA2D [62].

Fig. 3. Flowchart of the ALPA [63].

Fig. 4. Hierarchy of data illustrating the nomenclatures based on the concept of "Order" and "Ways". Top: data for a single sample. Bottom: data for a set of samples [77].

Fig. 5. Classification tree for three-way data for a set of samples, according to whether the individual data matrices are bilinear or not, and to the number of trilinearity-breaking modes [77].

Fig. 6. Classification tree for four-way data for a set of samples, according to whether the individual three dimensional arrays data are trilinear or not, and to the number of quadrilinearity-breaking modes [77].

Fig. 7. Cyclic voltammograms of (a) $2.0 \mathrm{mM} \mathrm{Co(phen)})_{3} \mathrm{Cl}_{2}$ and (b) $1.0 \mathrm{mM} \mathrm{Ru}(\mathrm{NH})_{3} \mathrm{Cl}_{3}$ in $0.1 \mathrm{M} \mathrm{KCl}$ at different scan rates [109].

Fig. 8. MCR-ALS derived cyclic voltammograms of (a) net faradaic, (b) step charging (c) induced charging and (d) total current contribution for $2.0 \mathrm{mM} \mathrm{Co(phen)}{ }_{3} \mathrm{Cl}_{2}$ in $0.1 \mathrm{M} \mathrm{KCl}$ at different scan rates [109].

Fig. 9. MCR-ALS derived cyclic voltammograms of (a) net faradaic, (b) step charging (c) induced charging and (d) total current contribution for $1.0 \mathrm{mM} \mathrm{Ru}\left(\mathrm{NH}_{3}\right)_{6} \mathrm{Cl}_{3}$ in $0.1 \mathrm{M} \mathrm{KCl}$ at different scan rates [109]. 
1

Fig. 10. Differential pulse voltammetric data corresponding to the calibration set. (A) Raw data. After preprocessing: (B) baseline correction and (C) alignment with COW [83].

Fig. 11. Normalized individual voltammograms (a) and concentration profiles (b) obtained from MCR-ALS optimization by applying the non-negativity, signal shape and selectivity constraints [173].

Fig. 12. SEM images of PdFeNi/ChRTIL/GCEs prepared by CV from a $0.2 \mathrm{~mol} \mathrm{~L}^{-1} \mathrm{KCl}$ solution containing $0.5 \times 10^{-3} \mathrm{~mol} \mathrm{~L}^{-1} \mathrm{PdCl}_{2}, 0.5 \times 10^{-3} \mathrm{~mol} \mathrm{~L}^{-1} \mathrm{NiCl}_{2}$ and $0.5 \times 10^{-3} \mathrm{~mol} \mathrm{~L}^{-1} \mathrm{FeCl}_{3}$. Number of cyclic scans $(N)$ : (A) 1 , (B) 2, (C) 4, (D) 8, (E) 12, (F) 16, (G) 20, (H) 24, and (I) 28 [95].

Fig. 13. Histograms of PSDs measured by DIP from the images presented in Fig. 12A-I [95]. 


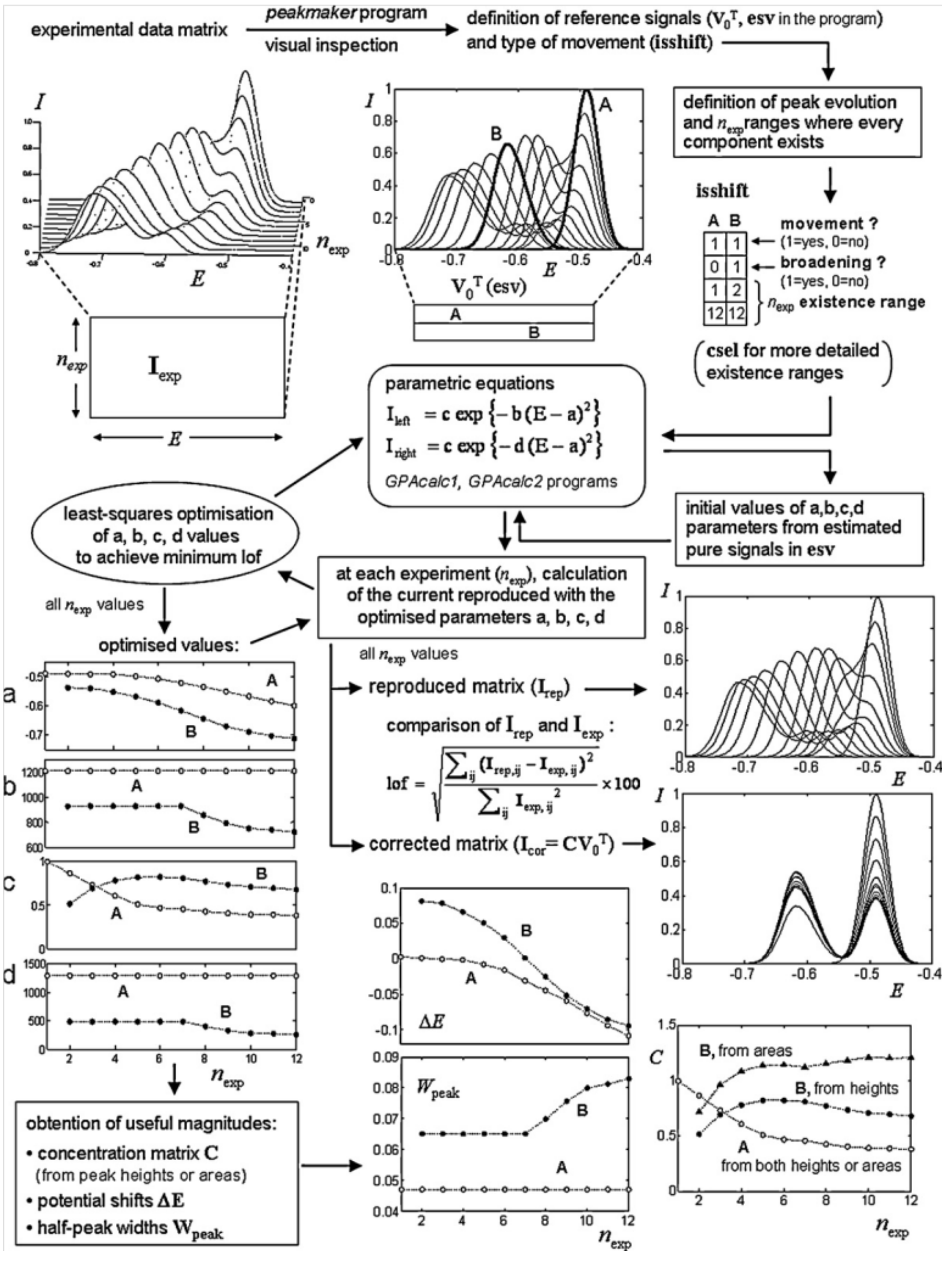

Fig. 1. 


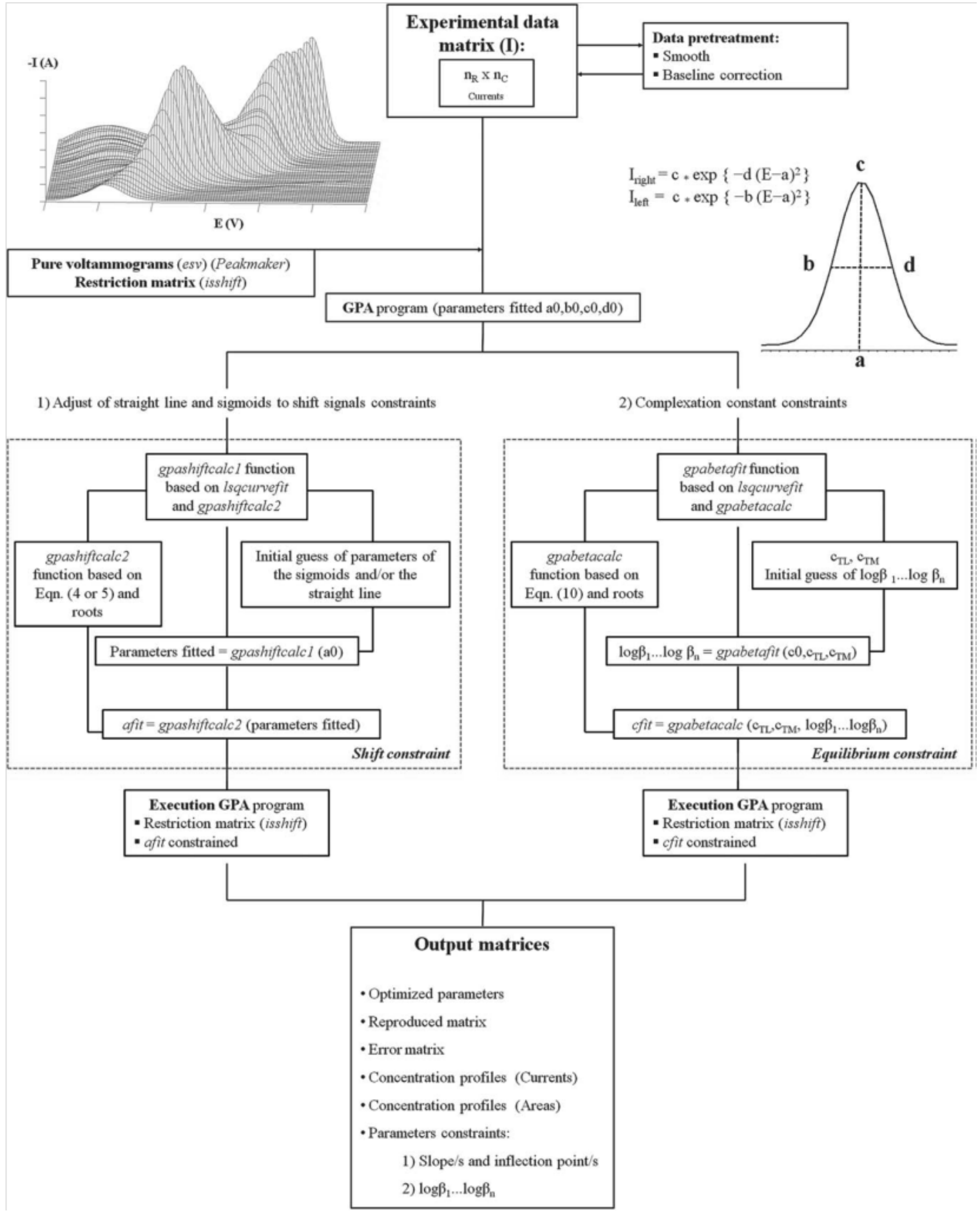

Fig. 2. 
experimental data matrix

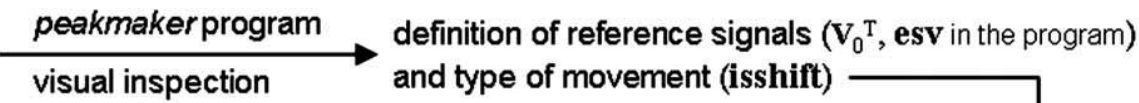

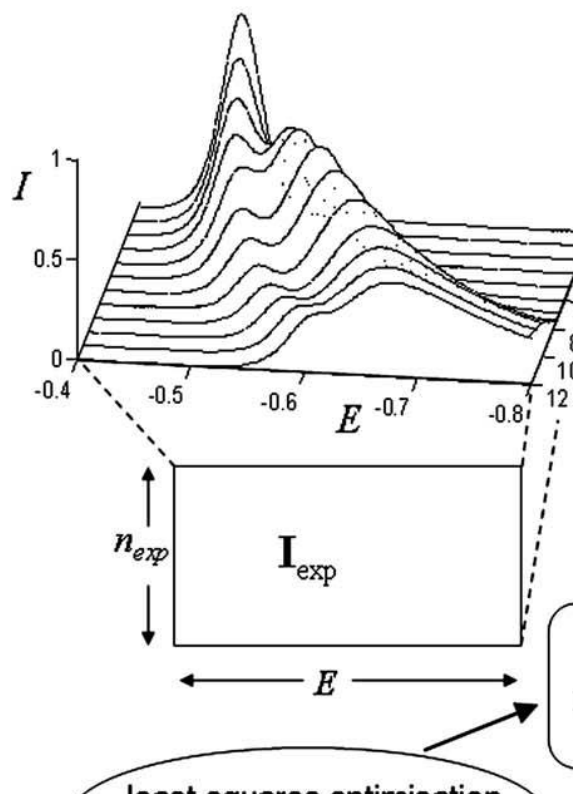

least-squares optimisation of $a, b, c, d$ values

all $n_{\exp }$ values

optimized values:
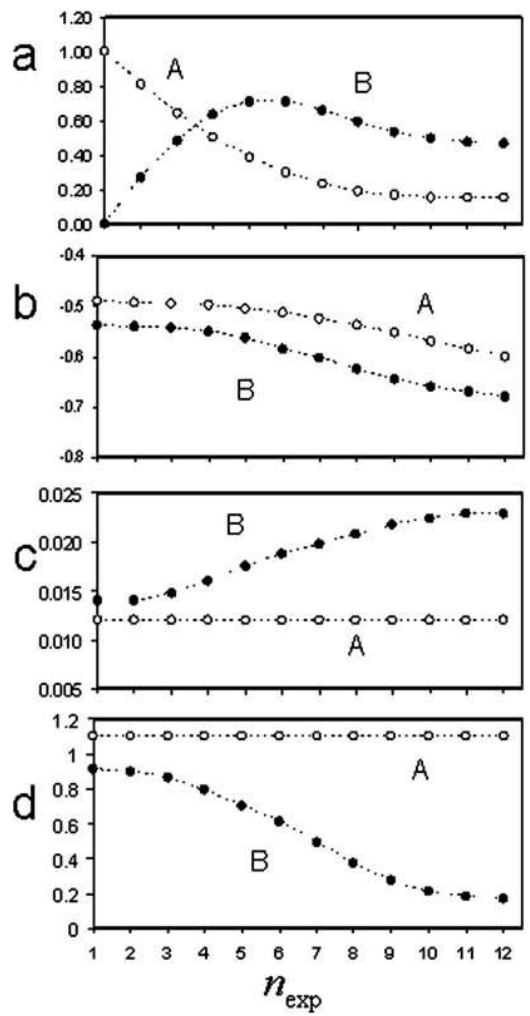

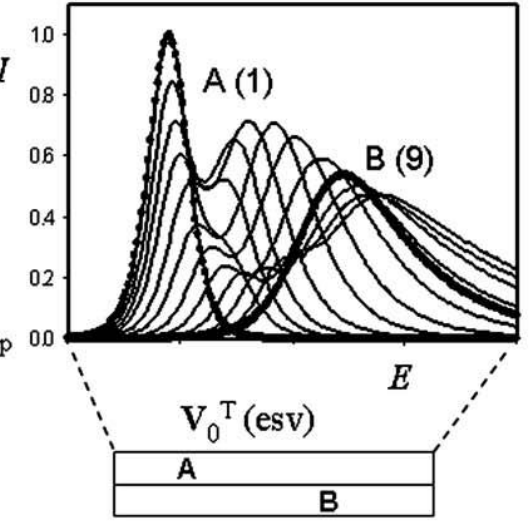

definition of peak evolution and $n_{\text {exp }}$ ranges where every component exists

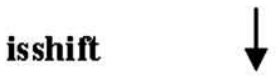

A B movement ?

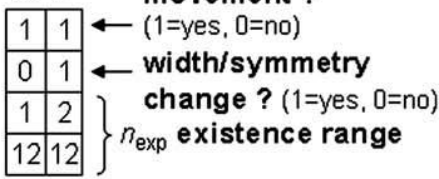

parametric equation

ALPAcaic program

$I=a\left[1+\exp \left(-\frac{E+c \ln d-b}{c}\right)\right]^{-d-1} d^{-d}(d+1)^{d+1} \exp \left(-\frac{E+c \ln d-b}{c}\right)$

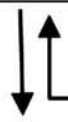

at each experiment $\left(n_{\text {exp }}\right)$, calculation of the current reproduced with the optimised parameters a, b, c, d

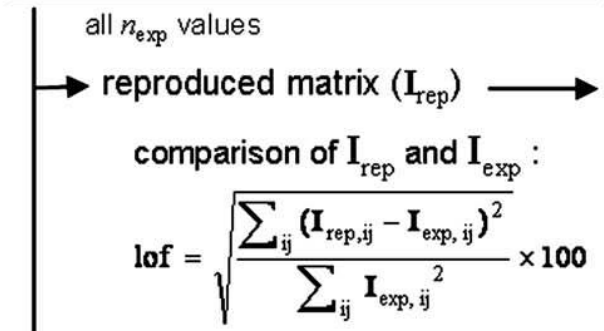

initial values of $a, b, c, d$ parameters from estimated pure signals in esv

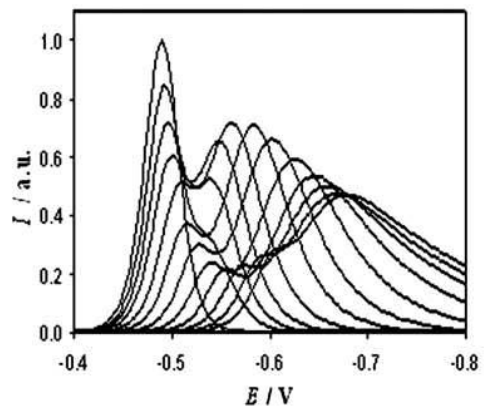

corrected matrix $\left(\mathrm{I}_{\text {cor }}=\mathrm{CV}_{0}^{\mathrm{T}}\right) \rightarrow$

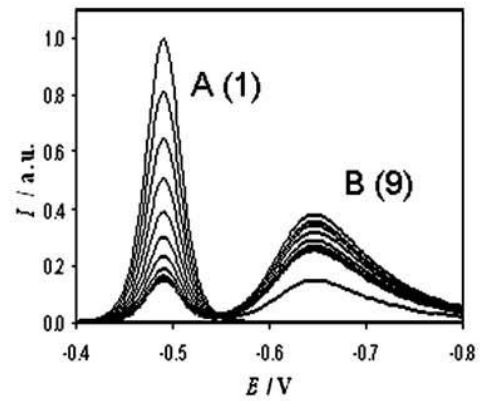

Fig. 3. 
Figure 4

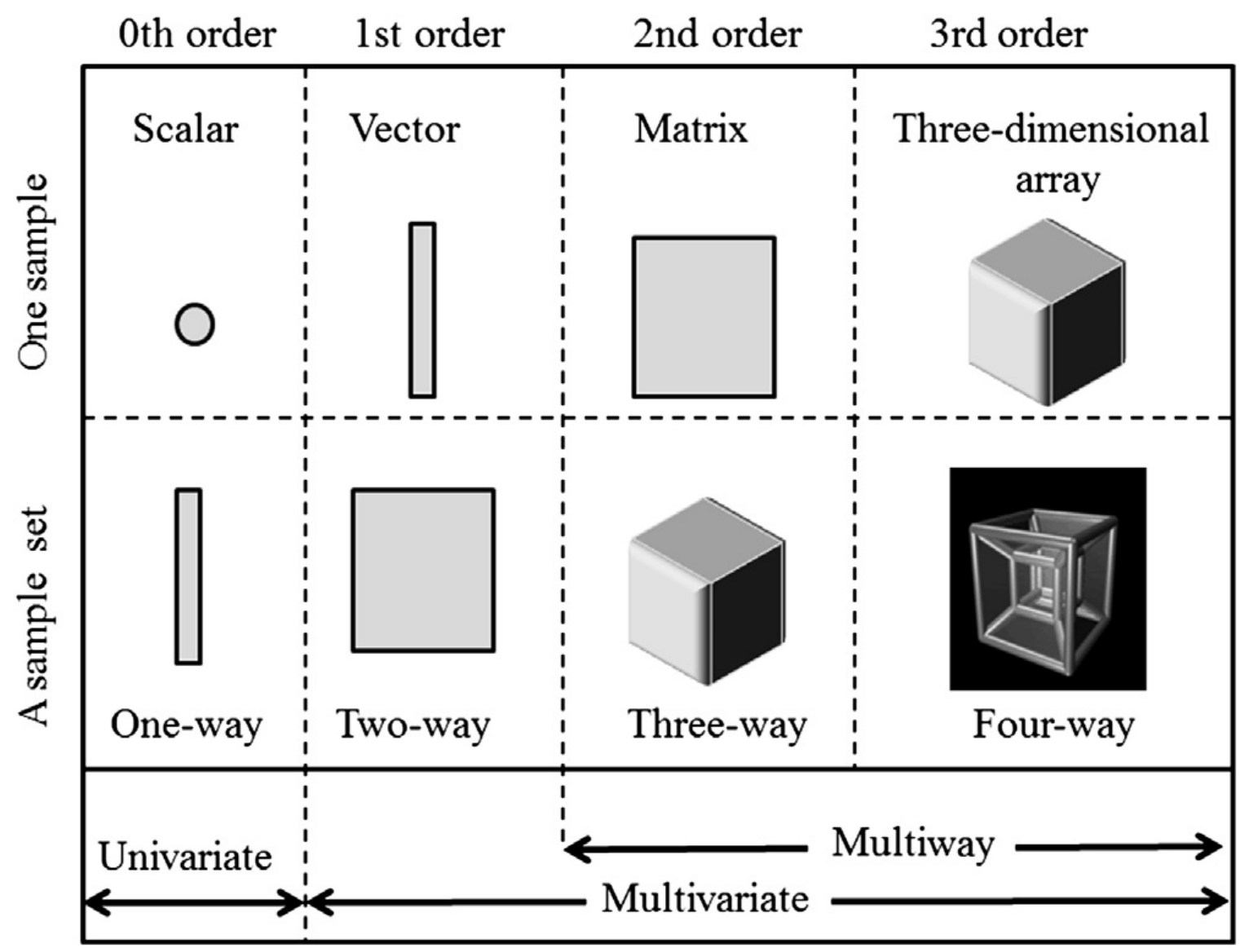

Fig. 4. 


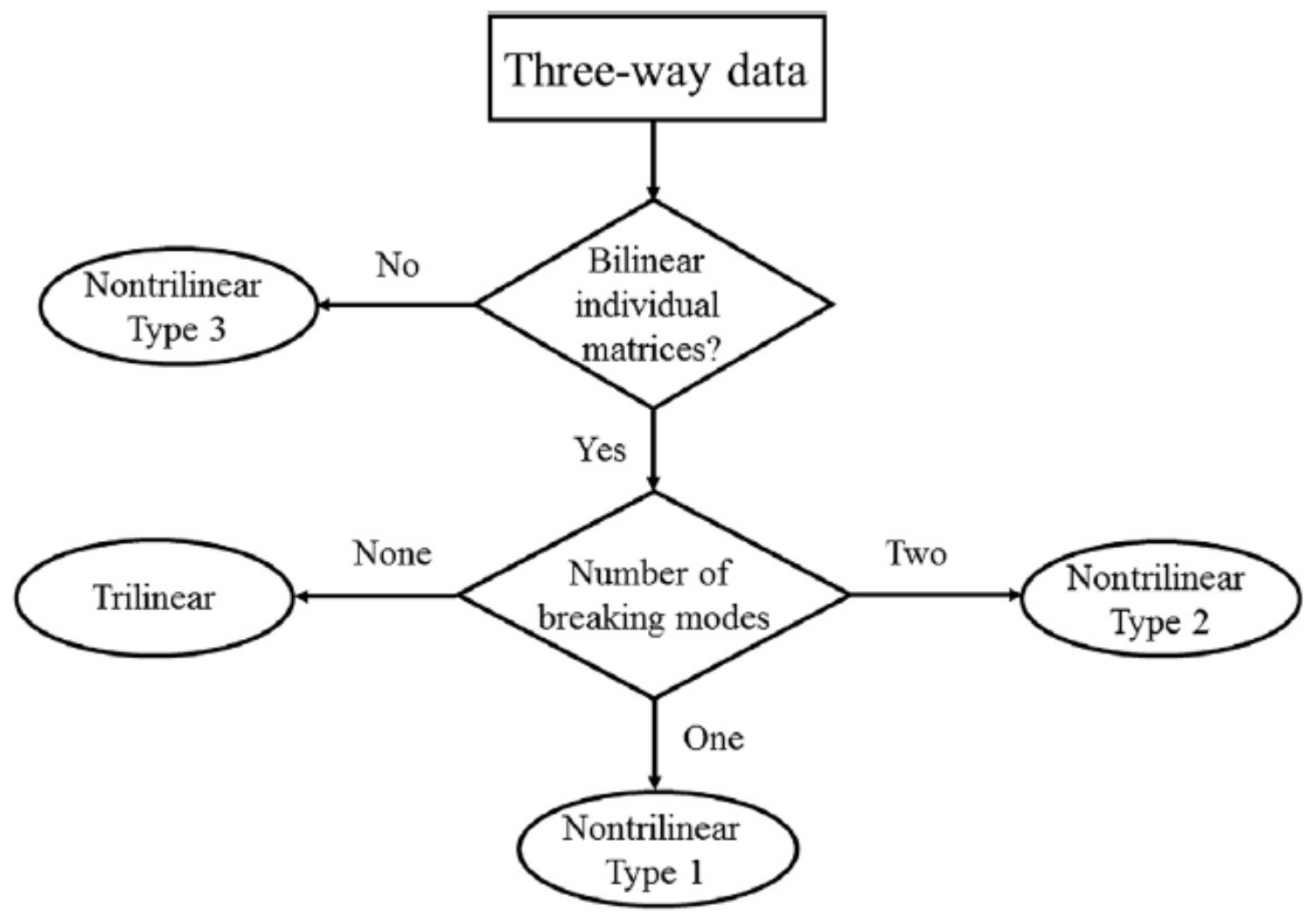

Fig. 5.

Figure 5 


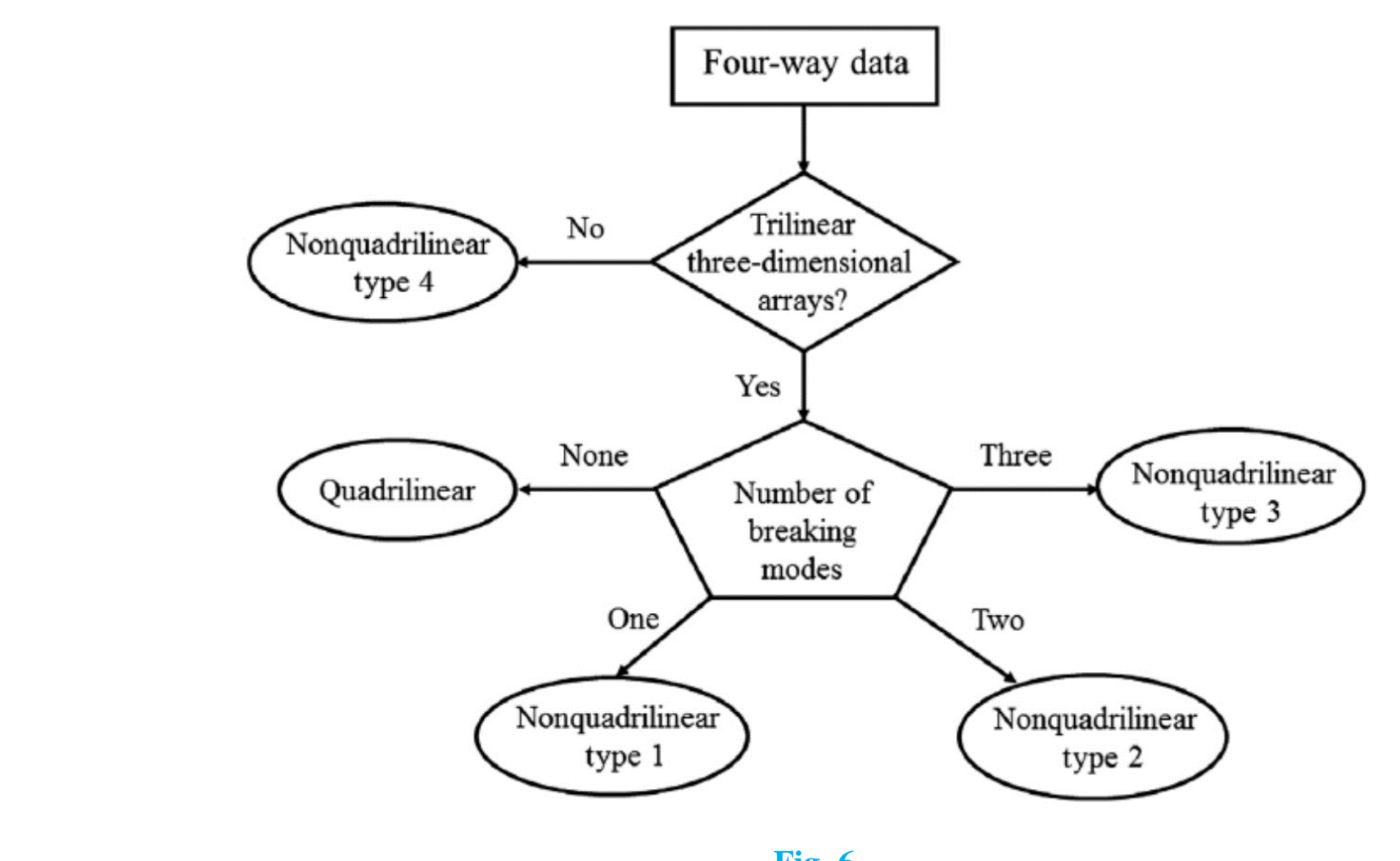

Fig. 6.

\section{Figure 6}

(

.

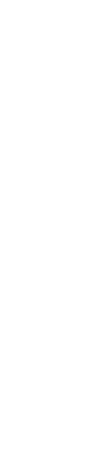

.

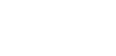

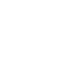
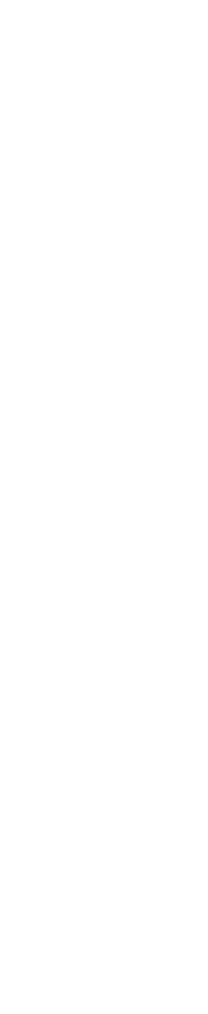

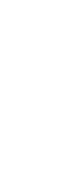



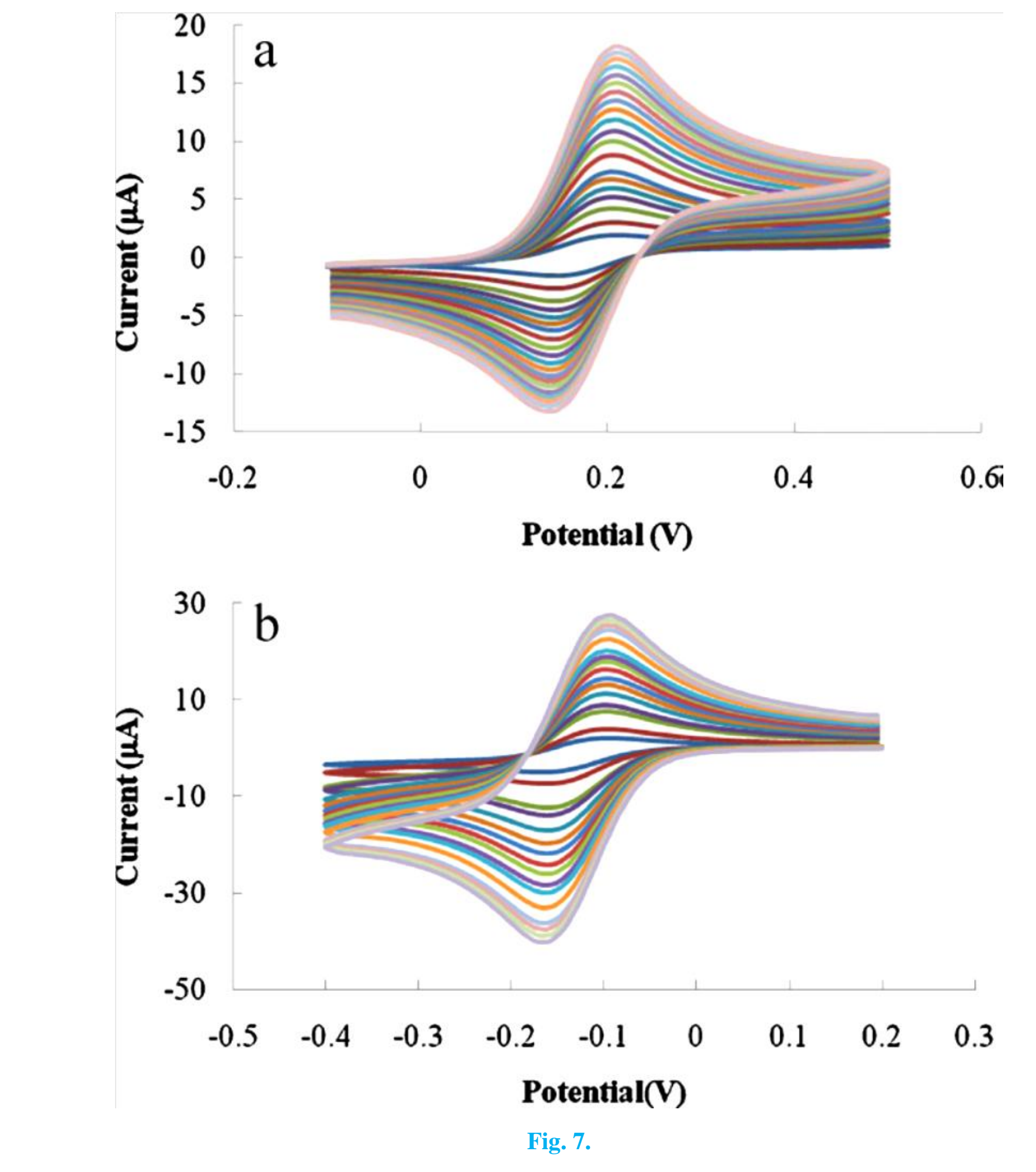

Fig. 7.

(

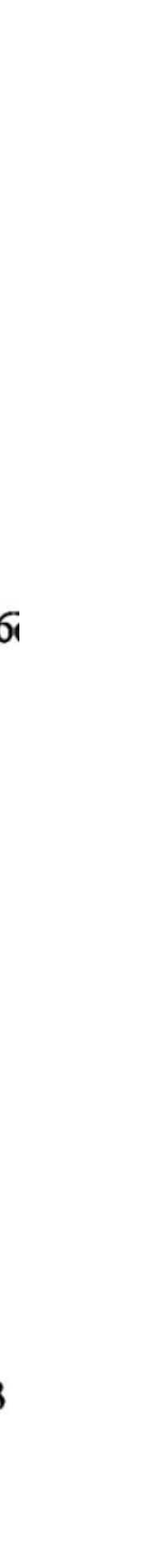

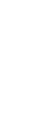
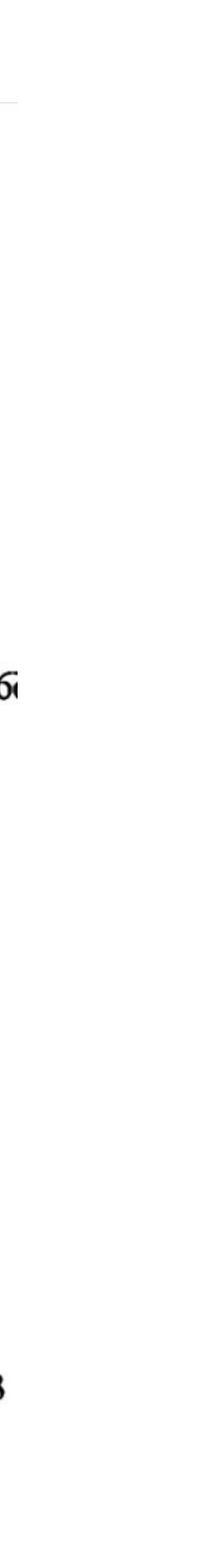
Figure 8
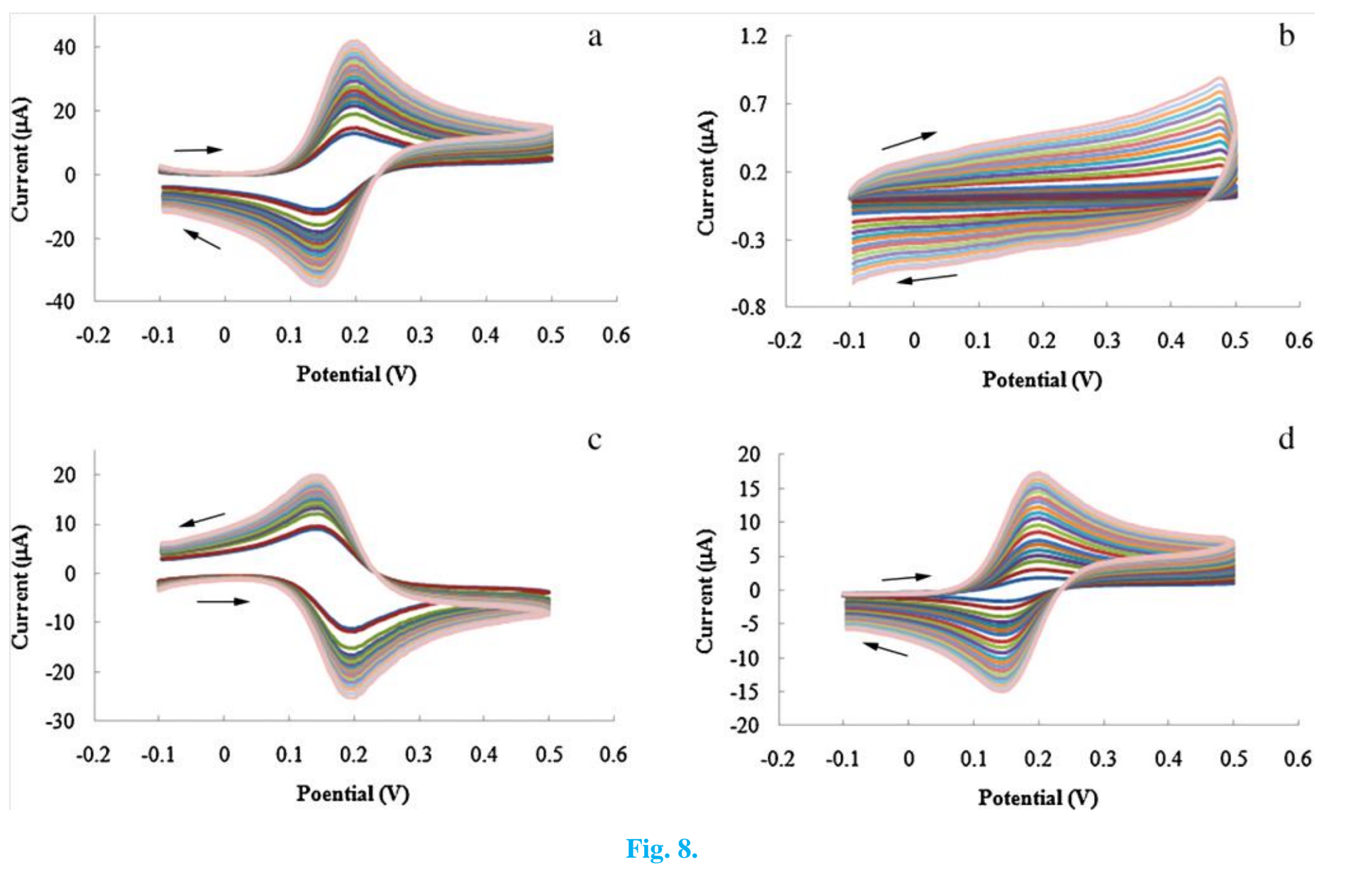

Fig. 8.

\footnotetext{
8.
}

\section{8}

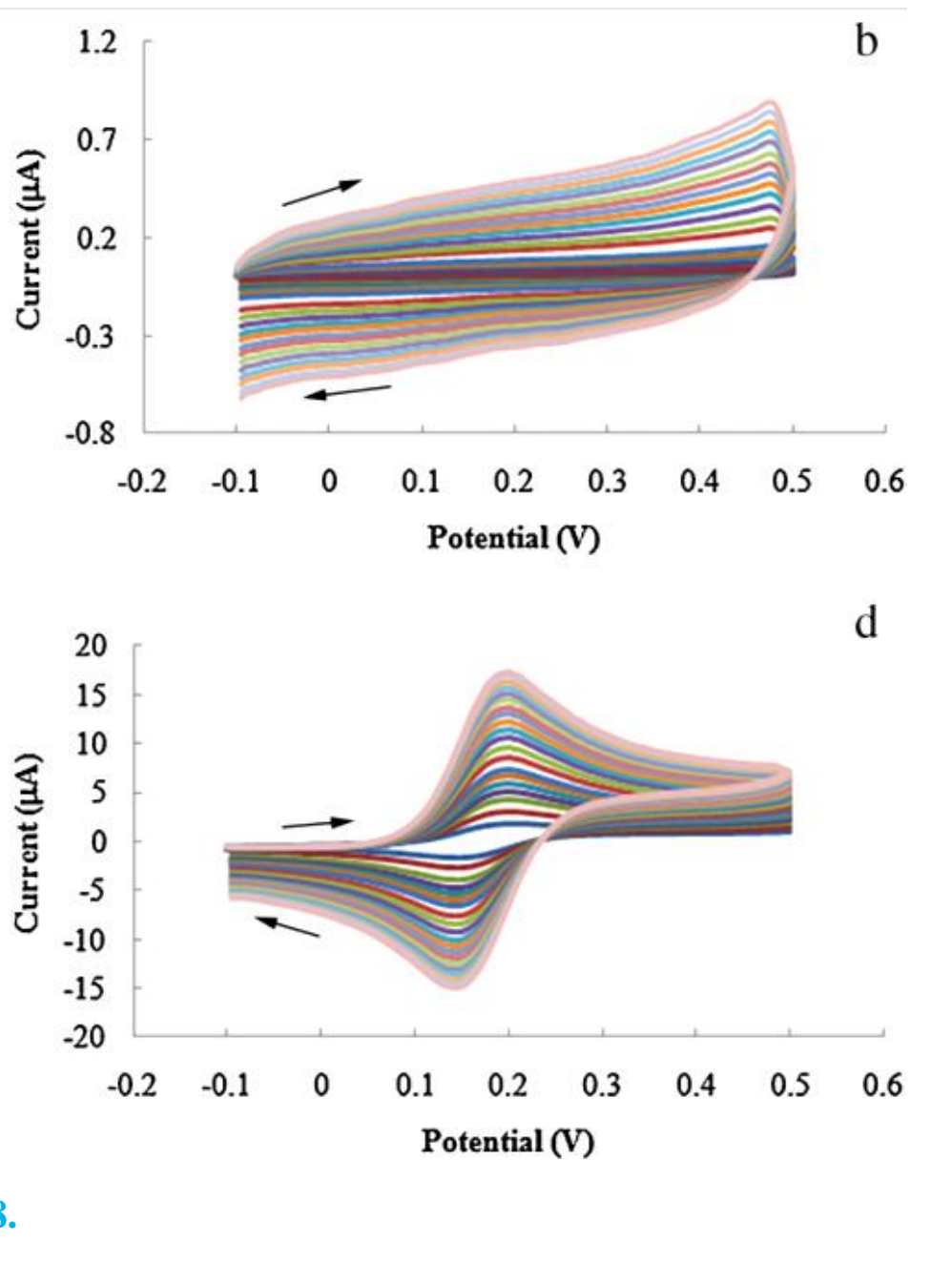


Figure 9
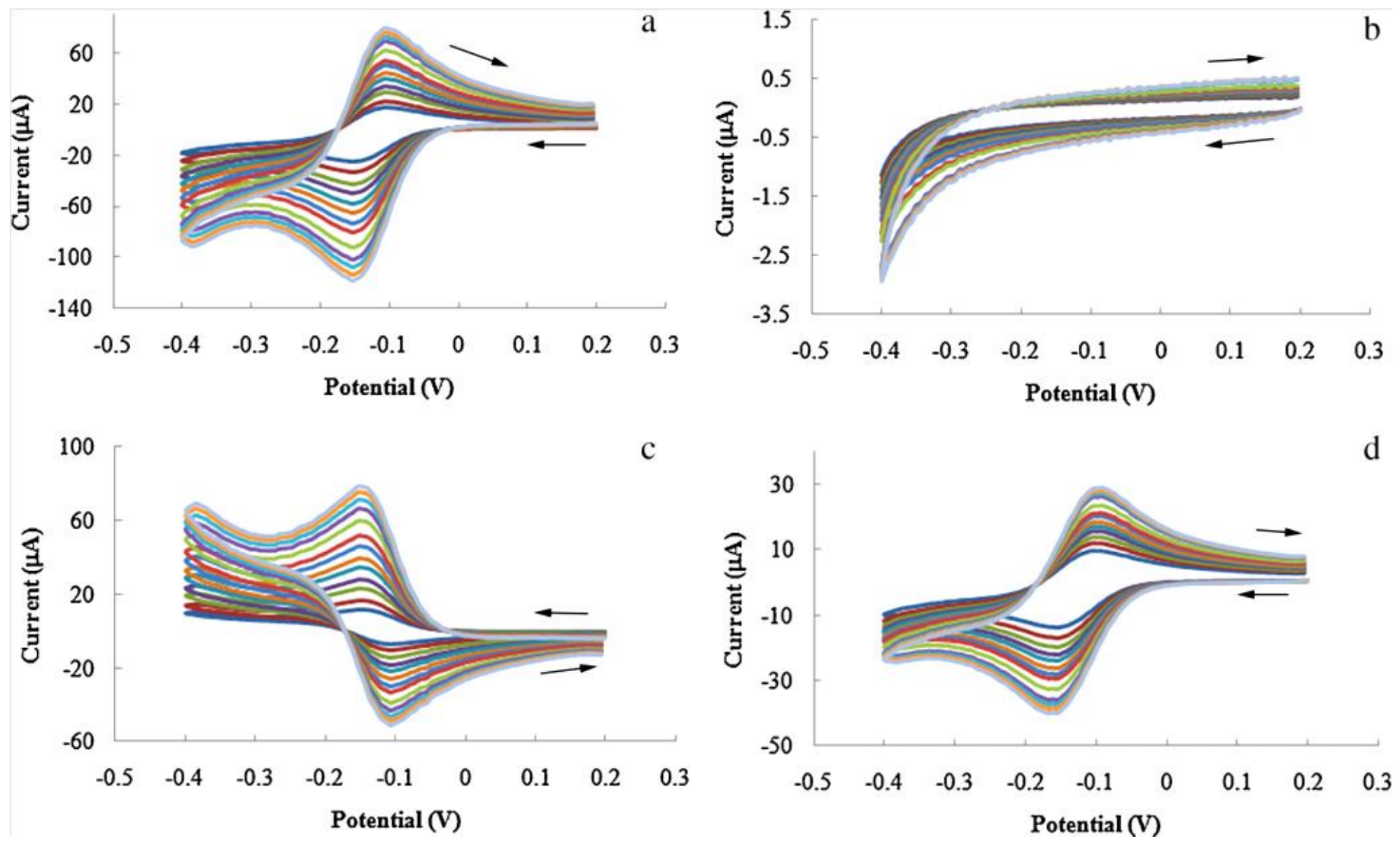

Fig. 9. 

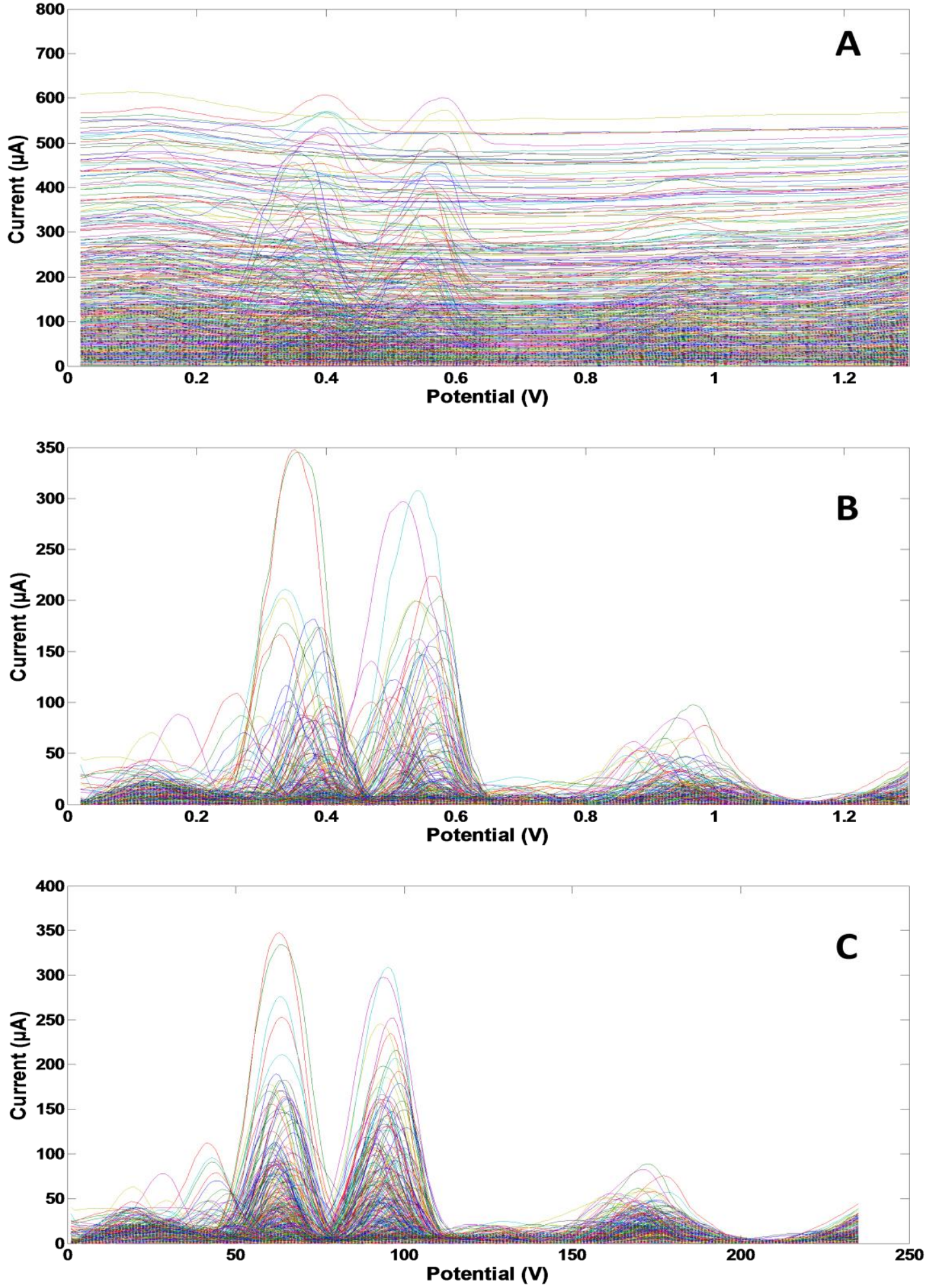

Fig. 10 . 


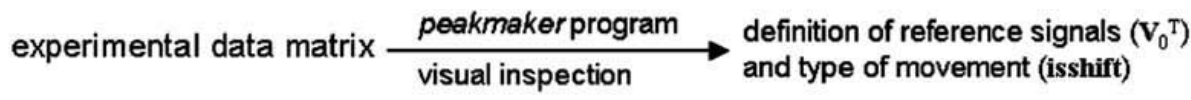

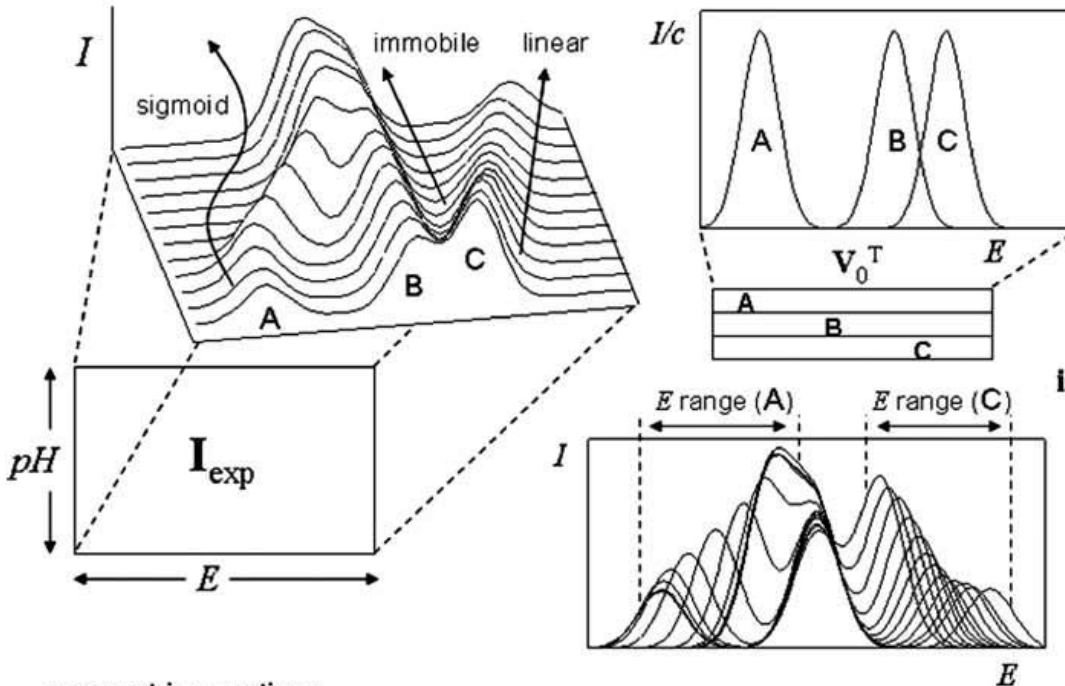

definition of $p H, E$ ranges where every component exists and/or can be used for initial estimations $p H$ ranges $\rightarrow$ isshift

$E$ ranges $\rightarrow$ mouse selection

A B C

\begin{tabular}{|l|l|l}
\hline 3 & 0 & 2
\end{tabular} movement type

isshift

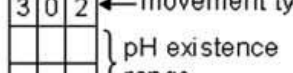

- range $\mathrm{pH}$ estimation \begin{tabular}{lll}
\hline & & range
\end{tabular}

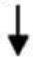

looking for relative maxima inside the ranges and $\Delta E$ estimation by comparison

parametric equations

$\left.\begin{array}{l}\Delta E(\mathrm{~A})=\frac{\mathrm{a}}{1+\mathrm{e}^{\mathrm{b}(p H-\mathrm{c})}+\mathrm{d}} \\ \Delta E(\mathrm{~B})=0 \\ \Delta E(\mathrm{C})=\mathrm{a}^{\prime}+\mathrm{b}^{\prime} p H\end{array}\right\}$
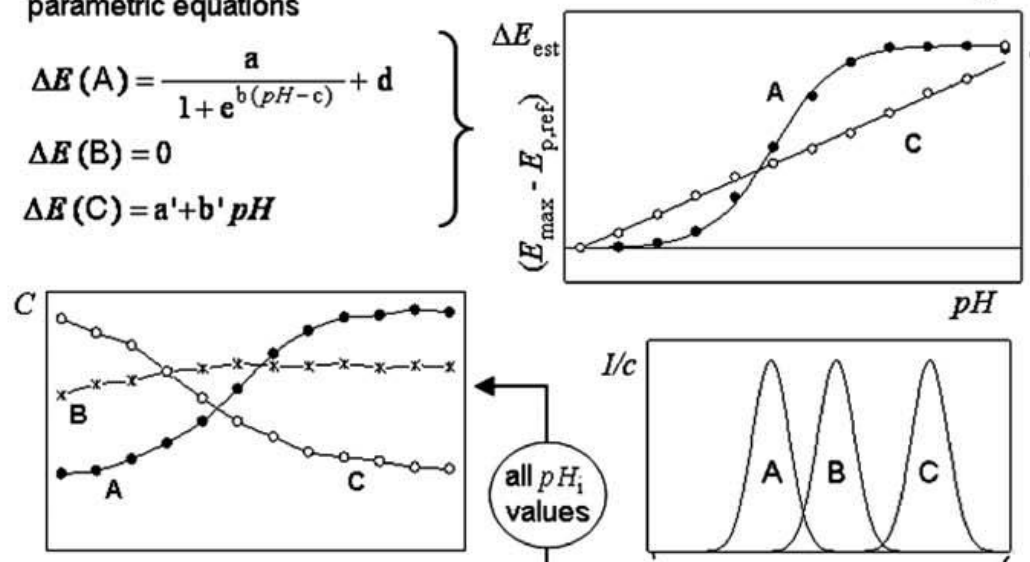

with reference signals

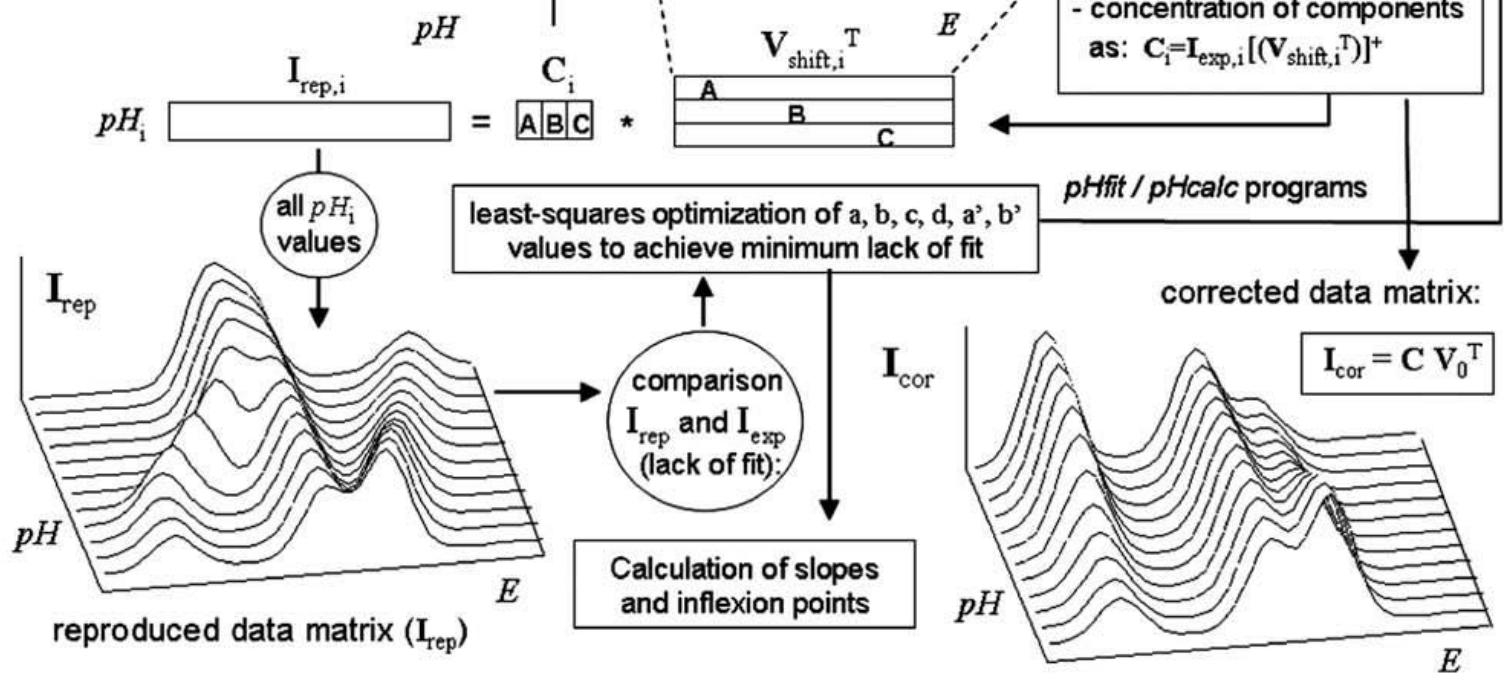

Fig. 11. 
A
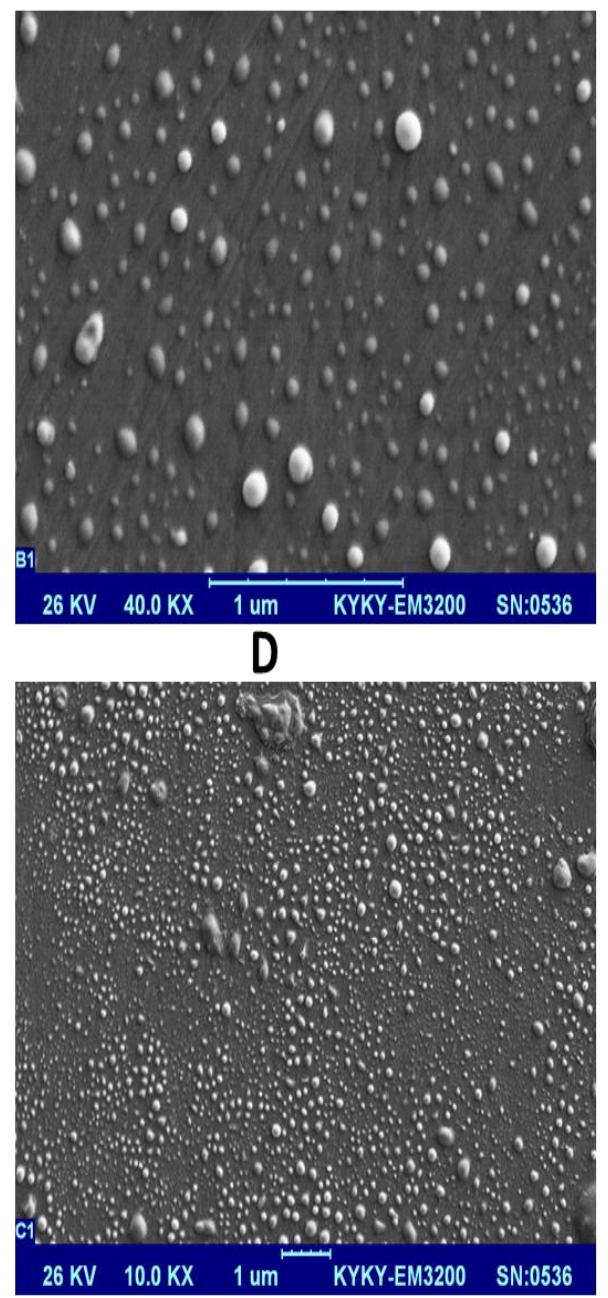

G

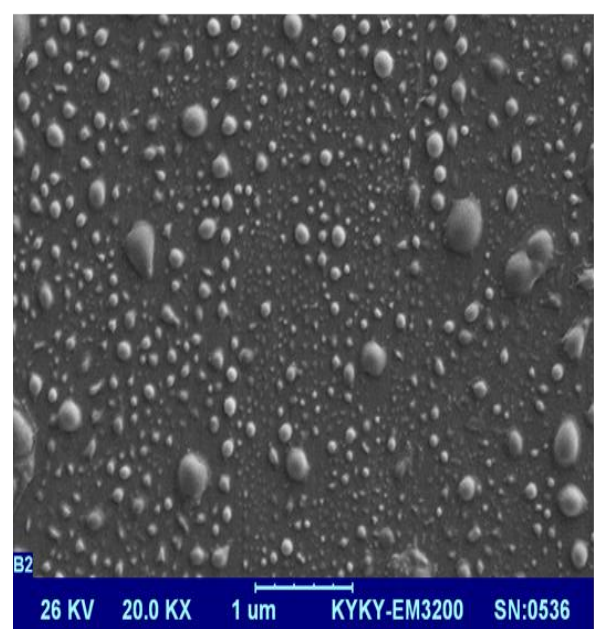

B
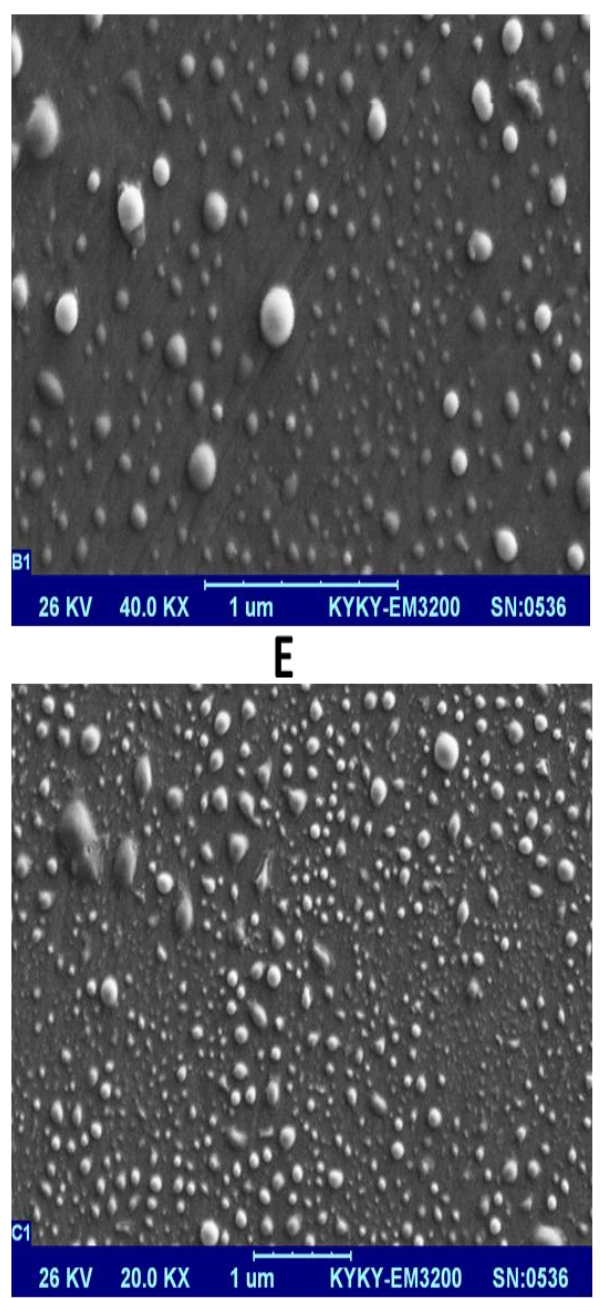

$\mathrm{H}$

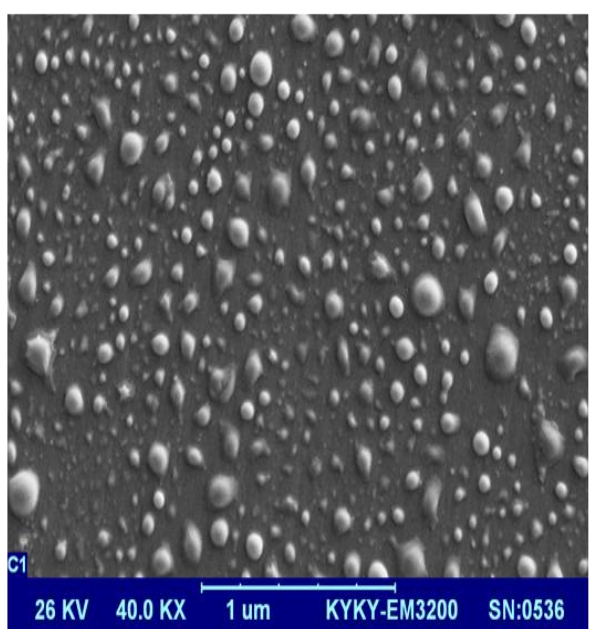

C
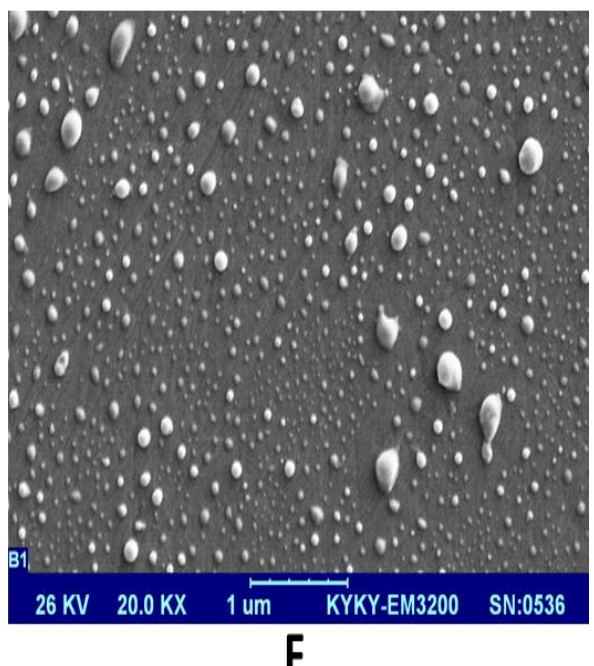

$26 \mathrm{KV} 40.0 \mathrm{KX} 1 \mathrm{um} \quad \mathrm{KYKY}$-EM3200 SN:0536

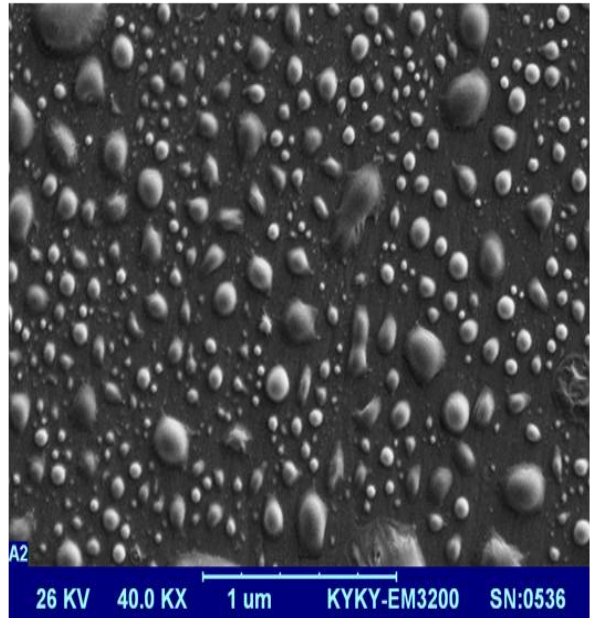

Fig. 12 . 

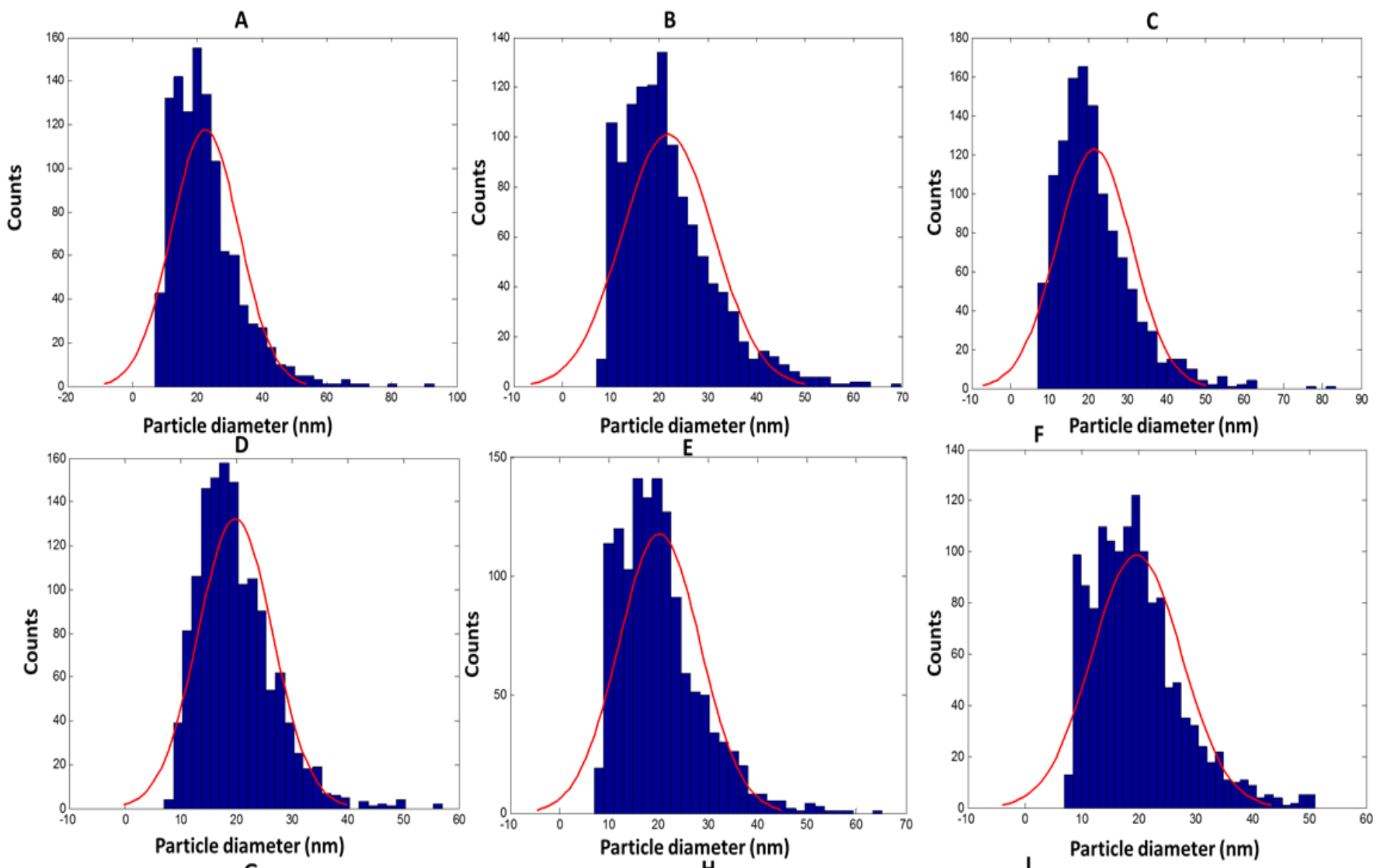

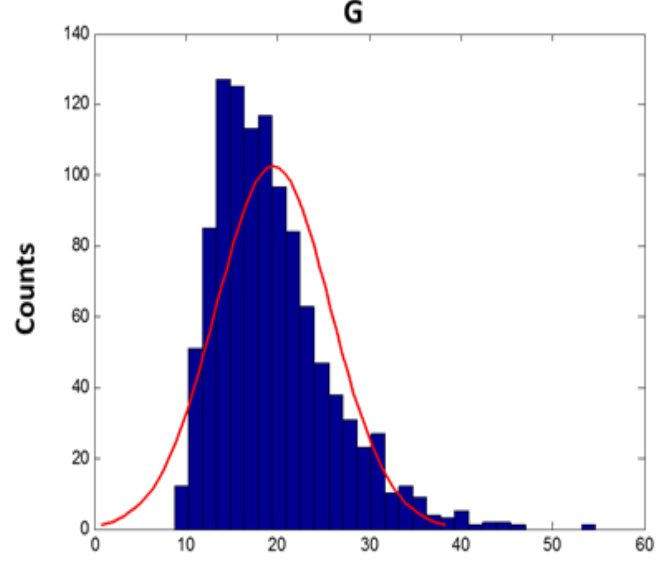

Particle diameter (nm)
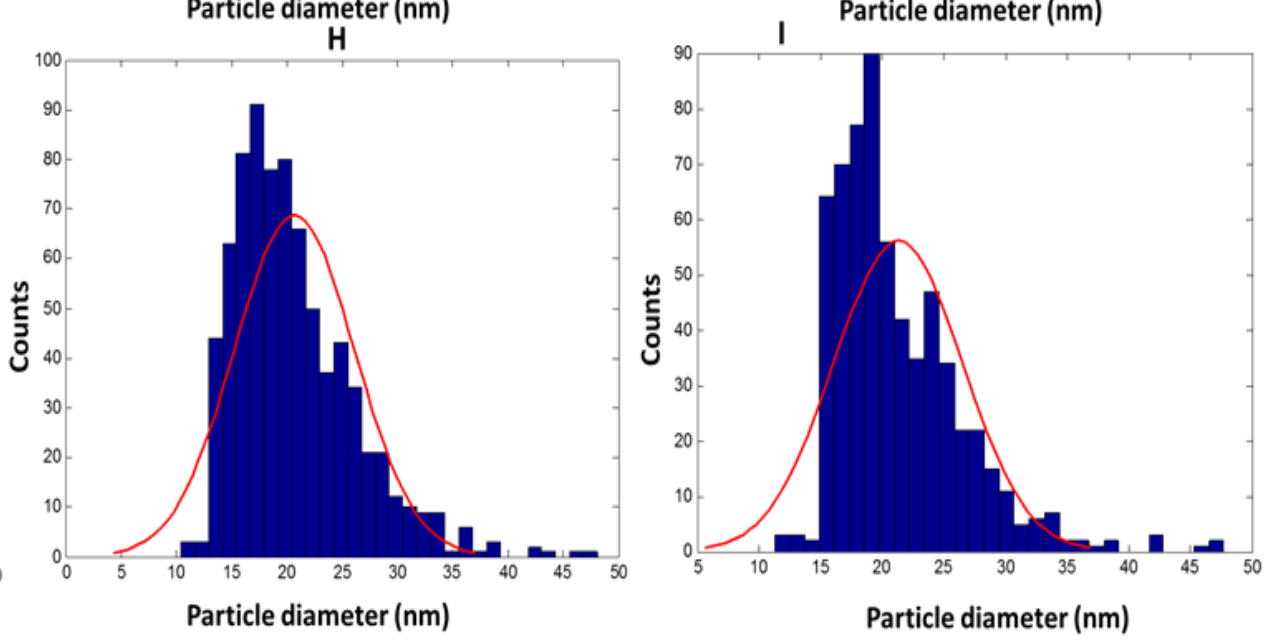

Fig. 13. 


\section{Checklist}

- E-mail address: ali.jalalvand1984@gmail.com

- Full postal address: Research Center of Oils and Fats, Kermanshah University of Medical Sciences, Kermanshah, Iran

- Telephone and fax numbers: Tel.: +988334302345, Fax: +988334279745

- Keywords: ok

- All figure captions: ok

- All tables (including title, description, footnotes): ok

- Further considerations

- Manuscript has been 'spell-checked' and 'grammar-checked': ok

- References are in the correct format for this journal: ok

- All references mentioned in the Reference list are cited in the text, and vice versa: ok

- Permission has been obtained for use of copyrighted material from other sources (including the Web): ok

- Color figures are clearly marked as being intended for color reproduction on the Web (free of charge) and in print, or to be reproduced in color on the Web (free of charge) and in black-and white in print: ok

- If only color on the Web is required, black-and-white versions of the figures are also supplied for printing purposes: ok 


\section{${ }^{*}$ List of Three Potential Reviewers}

\section{Dr. Alejandro C. Olivieri}

Departamento de Qui'mica Analı'tica, Facultad de Ciencias Bioqui'micas y Farmace'uticas, Universidad Nacional de Rosario, Suipacha 531, Rosario (S2002LRK), Argentina

E-mail address: aolivier@ fbioyf.unr.edu.ar

\section{Dr. Graciela Escandar}

Departamento de Qui'mica Analı'tica, Facultad de Ciencias, Universidad de Extremadura, Badajoz 06071, Spain E-mail address: escandar@iquir-conicet.gov.ar

\section{Dr. Mario Cesar Ugulino de Araujo}

Laboratório de Automação e Instrumentação em Química Analítica e Quimiometria (LAQA), Universidade Federal da Paraíba, CCEN, Departamento de Química, Caixa Postal 5093, CEP 58051-970 João Pessoa, PB, Brazil

E-mail address: laqa@quimica.ufpb.br 